\title{
La Cooperativa de servicios públicos en Andalucía como modalidad de sociedad de economía mixta local
}

\author{
$M^{a}$ Dolores Rego Blanco \\ Profesora Titular de Derecho Administrativo \\ Universidad Pablo de Olavide de Sevilla
}

SUMARIO: I. PLANTEAMIENTO: COOPERATIVAS DE SERVICIOS PÚBLICOS ¿COSA DEL PASADO? II. ELEMENTOS Y CARACTERIZACIÓN DE LAS SOCIEDADES COOPERATIVAS DE SERVICIOS PÚBLICOS. III. IMPACTO DE LA LEGISLACIÓN DE CONTRATOS PÚBLICOS EN LA GREACIÓN DE UNA GOOPERATIVA DE SERVICIOS PÚBLICOS. A. Vigencia del principio de libre adhesión y baja voluntaria. V PECULIARIDADES DEL CAPITAL SOCIAL DE ESTAS COOPERATIVAS. A. Estructura B. Aportaciones de la Entidad local promotora. VI. ORGANIZACIÓN, TOMA DE DECISIONES.Y CONTROL ADMINISTRATIVO SOBRE LAS CONDICIONES DE PRESTAGIÓN DEL SERVICIO. VII. CONCLUSIONES.

RESUMEN: este trabajo estudia la figura andaluza de la sociedad cooperativa de servicios públicos, que es una sociedad de economía mixta que puede emplearse como medio de gestión indirecta de servicios públicos en las Entidades locales. Estas cooperativas se rigen principalmente por Derecho Privado, pero presentan algunos aspectos jurídico-públicos que son a los que se presta atención. Así, se analiza el impacto de la legislación de contratos en la formación de estas sociedades, planteando cómo aplicar el principio cooperativo de libre adhesión y baja voluntaria. Trata igualmente de las especialidades del capital social de estas sociedades, así como el régimen de toma de decisiones y el problema de cómo asegurar un control público sobre la adecuada prestación del servicio público.

PALABRAS CLAVE: sociedad cooperativa de servicios públicos; gestión de servicios públicos; régimen local andaluz; sociedad de economía mixta.

ABSTRACT: This paper studies the Andalusian cooperative company of public services, which is a semi-private company that could be used for the indirect management of public services. The scope of the paper is the Andalusian local governments. These cooperatives are mainly ruled by Private Law, but there are some 
aspects where Public Law must be observed. Therefore, the paper studies the impact of the public contract legislation on the formation of the company and how to deal with the principle of "open doors". It also deals with the specialties of the social capital as well as the the decision-making process and the need of a public control on the implementation of the public service.

KEY WORDS: cooperative company of public services; indirect management of public services; Andalusian local government; semi-private company.

\section{PLANTEAMIENTO: COOPERATIVAS DE SERVIGIOS PÚBLICOS ¿COSA DEL PASADO?}

Existe una corriente que preconiza la utilización de las sociedades cooperativas como modalidad de prestación de servicios públicos, atraída por la gestión democrática y participativa que caracteriza a estas formas societarias. Hasta la fecha, sin embargo la viabilidad y éxito de estas propuestas está prácticamente por descubrir en nuestro entorno ${ }^{1}$ En las páginas que siguen se aporta una reflexión sobre las principales cuestiones jurídico-administrativas que plantea el modelo.

La primera de estas cuestiones es si la fórmula cooperativa está hoy desterrada como opción para la prestación de servicios públicos. Recordemos que la regulación originaria del art. 85 de la Ley 7/1985, de 2 de abril (LBRL) acerca de los modos de gestión de servicios públicos locales de carácter indirecto, mencionaba expresamente a las sociedades "(...) mercantiles y cooperativas legalmente constituidas cuyo capital social sólo parcialmente pertenezca a la Entidad local”². Esa alusión se perdió con la

Las características de estas sociedades cooperativas no las sitúan entre las de obligada comunicación al Inventario de Entes del Sector Público Local, según la Orden HAP/2105/2012, de 1 de octubre, por la que se desarrollan las obligaciones de suministro de información previstas en la Ley Orgánica 2/2012, de 27 de abril, de Estabilidad Presupuestaria y Sostenibilidad Financiera. En particular, téngase en cuenta que la participación pública en estas cooperativas viene limitado al 49\%. Refleja mejor la realidad de estas cooperativas el Registro de Cooperativas Andaluzas, de la Junta de Andalucía, de consulta pública incluso a través de internet (). Según consulta de mayo de 2017, solo hay inscritas dos cooperativas bajo la modalidad aquí estudiada, de las cuales, por la fecha de constitución, habría que descartar una, que data de 2013.

La cursiva es enfática. En la redacción originaria del art. 85 LBRL (comprensiva de la alternativa "sociedad mercantil o cooperativa") se encuentra la justificación de que un buen número de las leyes autonómicas aprobadas antes de la Ley 57/2003, de modernización del gobierno local, contengan la alusión a una sociedad de economía mixta bajo la fórmula de sociedad cooperativa. A diferencia de Andalucía, en ninguna de estas Comunidades Autónomas, sin embargo, se regula un tipo específico de sociedad cooperativa para la prestación de servicios públicos locales. Véanse en este sentido, el art. 198 de la Ley Foral 6/1990 de 2 de julio, de la Administración local de Navarra; el art. 308 de la Ley 5/1997, de 22 de julio, de Administración local de Galicia; el art. 216 de la Ley 7/1999, de 9 de abril, de Administración local de Aragón; art. 217 de la Ley 1/2003, de 3 de marzo de la Administración local de La Rioja; el art. 
reforma introducida por la Ley 57/2003, de 16 de diciembre, de medidas para la modernización del gobierno local, y a partir de entonces las formas de gestión indirecta de servicios públicos se remiten a la legislación de contratos públicos. No obstante, el art. 104.1 del Real Decreto Legislativo 781/1986, de 18 de abril (TRRL), mantiene intacta su dicción original, que dice: "Para la gestión indirecta de los servicios podrán las Entidades locales utilizar las formas de Sociedad mercantil o cooperativa cuyo capital social sólo parcialmente pertenezca a la Entidad” (cursiva enfática).

La derogada Ley 2/1999, de 31 de marzo, de Sociedades Cooperativas Andaluzas admitía que las entidades públicas con personalidad jurídica pudieran ser socios de las sociedades cooperativas andaluzas "para prestar servicios o realizar actividades relacionadas con su actividad" (art. 31.4). No regulaba, sin embargo, una clase específica de sociedad cooperativa para la gestión de servicios públicos. Una década más tarde se aprobó la Ley 5/2010, de 11 de junio, de Autonomía Local de Andalucía (LAULA) que ninguna referencia expresa hace a las cooperativas como modo de gestión de servicios públicos. Posteriormente, es en la Ley 14/2011, de Sociedades Cooperativas Andaluzas (LSCA) donde aparece preconfigurada la sociedad cooperativa de servicios públicos ${ }^{3}$, remitiendo al reglamento su definición y régimen. Cumpliendo el mandato legal, el Decreto 123/2014, de 2 de septiembre, por el que se aprueba el Reglamento de la Ley 14/2011, de 23 de diciembre, de Sociedades Cooperativas Andaluzas (en adelante RSCA), determina en su art. 101 que las Administraciones territoriales andaluzas podrán proveer "la prestación directa de éstos [servicios públicos] mediante la constitución de sociedades cooperativas de servicios públicos."

Es cuanto menos llamativo que el RSCA afirme que la finalidad de la sociedad cooperativa de servicios públicos es la "prestación directa" de los servicios públicos, cuando una cooperativa no encaja en los modos propios de gestión directa de servicios públicos. De estos, el que pudiera acercarse más a la cooperativa que estudiamos sería, en Andalucía, una sociedad mercantil local, que no puede legalmente tener forma de sociedad cooperativa de servicios públicos. Según la LAULA “(l)a sociedad mercantil local deberá adoptar alguna de las formas de sociedad mercantil con res-

266 del Decreto Legislativo de 2/2003, de 28 de abril, por el que se aprueba el Texto Refundido de la Ley Municipal y de Régimen Local de Cataluña; el art. 171 de la Ley 20/2006, de 15 de diciembre, Municipal y Régimen Local de Illes Balears; el art. 295 del Decreto 179/1995, de 13 de junio, por el que se aprueba el Reglamento de Obras, Actividades y Servicios de las Entidades locales de Cataluña; o el art. 315 del Decreto 347/2002, de 19 de noviembre, por el que se aprueba el Reglamento de Bienes, Actividades, Servicios y Obras de las Entidades locales de Aragón.

3 Junto con la LSCA, solo tiene una clase cooperativa específica para servicios públicos la legislación valenciana (Decreto Legislativo 2/2015, de 15 de mayo), si bien con menor regulación, cuantitativamente hablando. El resto de Comunidades Autónomas y la Ley estatal de cooperativas desconocen la figura. 
ponsabilidad limitada y su capital social será íntegramente de titularidad directa o indirecta de una entidad local" (art. 38.3). Hay dos obstáculos que impiden plantear una interpretación de esta norma en la que la expresión "sociedad mercantil" comprendiera a las sociedades cooperativas: el primero es que una sociedad cooperativa no puede ser de socio único, ni tampoco, por consiguiente, su capital puede pertenecer íntegramente a un Ente público (art. 10 LSCA); y el segundo es que la LBRL, en su art. 85 ter.2, dispone el deber de la sociedad mercantil local de "adoptar una de las formas previstas en el texto refundido de la Ley de Sociedades de Capital aprobado por el Real Decreto Legislativo 1/2010, de 2 de julio (...)". Ha de entenderse, pues, que la expresión "prestación directa" de los servicios públicos del RSCA no se usa en términos técnico- jurídicos (equivalente a una gestión directa), sino en términos coloquiales, sinónimos, sin más, de la prestación misma del servicio.

En el contexto de los modos de gestión indirecta, habría que buscar acomodo a la sociedad cooperativa de gestión de servicios públicos en la legislación básica de contratos, por un lado (cuyo contenido hace suyo, la LBRL), y en la legislación autonómica andaluza, en segundo. La nueva Ley 9/2017, de 8 de noviembre de Contratos del Sector Público (LCSP), que transforma el contrato de gestión de servicios públicos en contratos de servicios o de concesión de servicios, mantiene la figura de la sociedad de economía mixta y nada dice de cuál haya de ser su forma societaria. Le basta a su DA $22^{\text {a }}$ con que sea una sociedad "en la que concurra mayoritariamente capital público con capital privado". Eso permite cobijar a su amparo tanto sociedades mercantiles de capital como de otro tipo, en nuestro caso, cooperativas.

Por su parte, el art. 43 de la LAULA precisa que "La empresa mixta es una sociedad mercantil con limitación de responsabilidad cuyo capital sólo parcialmente pertenece, directa o indirectamente, a la entidad local". Se plantea así la cuestión de si la expresión "sociedad mercantil" debe contraponerse a "sociedad cooperativa", como hacía originalmente la LBRL (con la consiguiente conclusión de que las cooperativas para gestión de servicios públicos son cosa del pasado), o puede, por el contrario, albergar tanto sociedades de capital como sociedades cooperativas. La segunda de las opciones se propone como la más adecuada actualmente, si tenemos en cuenta una serie de razones.

Por un lado, habida cuenta de la regulación vigente, la doctrina mercantilista cuestiona hoy la afirmación de que las sociedades cooperativas carezcan de naturaleza mercantil, para sentar, precisamente, la compatibilidad entre el mercantilismo y la economía social, propia de las cooperativas ${ }^{4}$. Por otro lado, a diferencia de lo

\footnotetext{
Muy ilustrativas, en este sentido, son las reflexiones de MORILLAS JARILLO en su trabajo "Concepto y clases de cooperativas" en PEINADO GARCÍA y VAZQUEZ RUANO: Tratado de derecho de cooperativas. Tomo I. Tirant lo Blanch, 2013, p. 115 y ss. Allí, tras repasar las tres corrientes existentes a
} 
que ocurre con la sociedad mercantil local (a la que la LBRL impone una forma societaria de capital), la concreta forma de la sociedad de economía mixta no se predetermina ni en la legislación básica estatal (local o de contratos públicos) ni en tampoco en la LAULA.

Por tanto, aunque según la LAULA la sociedad de economía mixta es una sociedad mercantil, cabe defender que no estamos ante una prohibición taxativa de la forma cooperativa. LAULA y LSCA pueden leerse como normas complementarias, dada la compatibilidad de ambas posibilidades (sociedad mercantil de capital y sociedad cooperativa) con la legislación básica estatal, y la limitación de responsabilidad de las sociedades cooperativas, como desea la LAULA que tengan las sociedades de economía mixta. Esta conclusión se refuerza si la cuestión se contempla desde la competencia estatutaria de la Comunidad Autónoma (art. 60.1.c) para regular el régimen local andaluz, incluidas otras fórmulas diversas de gestión de los servicios públicos que sean conformes con el ordenamiento ${ }^{5}$.

\section{ELEMENTOS Y GARACTERIZACIÓN DE LAS COOPERATIVAS DE SERVICIOS PÚBLICOS}

La LSCA crea el nomen iuris de sociedades cooperativas de servicios públicos pero no dota a esta nueva clase de cooperativa ni de un régimen jurídico, ni de una definición (art. 107). Se conforma con ordenar su regulación reglamentaria, en su calidad de sociedad cooperativa de primer grado, de carácter especial. El único límite sustantivo que la LSCA establece para la tarea que remite al reglamento es que, de acuerdo con su art. 107, el tipo de sociedad cooperativa resultante, como sociedad

propósito de la naturaleza de las sociedades cooperativas (que abogan, respectivamente, por su carácter asociativo, su naturaleza de sociedad mercantil o por su entendimiento como tertium genus - empresa de economía social), se defiende el carácter mercantil de las sociedades cooperativas. En síntesis, los principales argumentos de esa conclusión son: a) que en la legislación cooperativa ha dejado de ser un requisito esencial el carácter no lucrativo de la sociedad para poder considerarse sociedad cooperativa, pues las que no tienen tal ánimo pasan a configurar una clase especial de cooperativas; b) la relativización del lucro como elemento esencial del concepto de sociedad; c) y la aproximación entre los regímenes jurídicos de las cooperativas y de las sociedades mercantiles; y d) la compatibilidad entre "mercantilismo" y "economía social". En contraposición a esta opinión puede traerse a colación la STC 72/1983, en la que se afirma que el hecho de que se aplique parcialmente a las sociedades cooperativas la normativa mercantil no las convierte en sociedades mercantiles, pues de ser así las Comunidades Autónomas carecerían de competencia para su regulación, al ser ésta exclusiva del Estado.

Es pacíficamente aceptado el carácter abierto de las modalidades de gestión de servicios públicos, como consecuencia natural de la faceta de autoorganización (art. 4.1.a LBRL) de la autonomía local constitucionalmente garantizada (art. 137). Así, MORILLO-VELARDE PÉREZ: "La gestión de los servicios de las Entidades locales" en COBO OLVERA (Dir): Tratado de Derecho Local. Thomson Reuters-Aranzadi, 2010, p. 1289 o SOSA WAGNER: "La gestión de los servicios públicos mediante una sociedad de capital íntegramente público y mediante una sociedad mixta" en Cuadernos de Derecho Local, núm. 7, 2005, p. 14. 
cooperativa especial, no coincida con el resto de sociedades cooperativas de primer grado establecidos en el capítulo II del título II de la Ley.

Es el RSCA el que aporta los elementos subjetivos y objetivos para poder identificar las notas características de las sociedades cooperativas de servicios públicos. Su art. 101 dice:

"1. La Administración de la Junta de Andalucía así como las Administraciones locales andaluzas, a fin de asegurar la existencia de servicios públicos de calidad, podrán proveer que la prestación directa de éstos se haga mediante la constitución de sociedades cooperativas de servicios públicos.

2. En estas sociedades cooperativas participarán como personas socias promotoras la entidad o entidades públicas competentes y, en su caso, entidades privadas con experiencia demostrada en el sector; asimismo, podrán participar las personas usuarias de los servicios que sean objeto de la sociedad cooperativa así como las personas socias trabajadoras que presten su trabajo personal en la sociedad, en este último caso hasta alcanzar el veinticinco por ciento del capital de la misma. No obstante, las entidades públicas promotoras conservarán el control en cuanto a las condiciones de prestación de los servicios públicos.

\section{(...).}

3. Se excluye, en todo caso, la prestación de servicios públicos que exijan el ejercicio de autoridad pública, como los de orden público y protección civil. (...)"

El elemento subjetivo de la cooperativa de servicios públicos destaca por la gran flexibilidad en la configuración societaria. Cabe integrarla por socios que sean entidades públicas, empresarios, trabajadores o usuarios de los servicios públicos, lo que hace pensar que lo habitual será que supere el mínimo legal de tres socios (art. 10 LSCA). Aunque el reglamento parece distinguir entre socios promotores (entidad pública, y en su caso, empresarios experimentados), y otros que no lo sean (socios usuarios y trabajadores), no puede descartarse que sea una referencia gratuita, pues el texto reglamentario no configura una prohibición de actuar como promotores a los socios usuarios y a los socios trabajadores, ni tampoco una limitación sobre los otros socios para que no puedan desempeñar otro papel en la vida de la cooperativa que el de mero promotor.

Sí tiene más sentido la diferenciación por el reglamento entre socios potestativos y preceptivos. La presencia de una entidad pública es obligada en la promoción y desarrollo de la cooperativa de servicios públicos. El único tipo de socio del que no se puede prescindir a lo largo de la vida de esta clase de cooperativa es la entidad 
pública que sea competente para presar el servicio cuya gestión desea cooperativizarse. El carácter preceptivo se aprecia en el modo imperativo del verbo empleado por el reglamento ("participarán" la entidad o entidades públicas competentes), pero también en que sin la presencia de una entidad pública no cabría hablar de sociedad de economía mixta o de colaboración público-privada.

La entidad pública socia bien podría ser autonómica o incluso, estatal, siempre que la actividad societaria, la gestión del servicio público en nuestro caso, se desarrollara mayoritariamente en Andalucía ${ }^{6}$. Como quiera que sea, recordemos que este estudio se restringe al ámbito local andaluz y por tanto, no se contemplará otra hipótesis que la de que la entidad pública socia sea local andaluza.

Detengámonos en la expresión "entidad pública” del art. 101 RSCA para preguntarnos a qué concretos sujetos del sector público se refiere la norma. Hablar de "entidad pública" resulta menos restrictivo que hacerlo de una "Entidad de Derecho Público”. Por ello, podría aceptarse, en principio, que el RSCA esté aludiendo tanto las personas jurídico-publicas, como a las denominadas "Entidades instrumentales de Derecho Privado" del sector público, donde se engloban las sociedades mercantiles y fundaciones del sector público. Esta conclusión se ve confirmada por el art. 43 LAULA, que al ocuparse de las sociedades de economía mixta, afirma que "(l) os entes locales pueden gestionar los servicios locales de interés económico general mediante la constitución o participación en empresas mixtas", pero no limita a las entidades locales propiamente dichas esa participación, puesto que añade que el capital de la empresa mixta sólo parcialmente pertenece, directa o indirectamente, a la entidad local. La conjunción de esta determinación de la LAULA con la LSCA y el RSCA, deja, por tanto, vía libre a que sea una entidad instrumental, de derecho privado o de derecho público, la que se integre como socio en una cooperativa andaluza de servicios públicos. Sin embargo, por exigencias de la legislación básica local, es obligado hacer una doble restricción.

En efecto, desde su modificación por la Ley 27/2013, de 27 de diciembre, de racionalización y sostenibilidad de la Administración Local, la Disposición Adicional Novena de la LBRL limita a los Municipios, Provincias y organismos autóno$\operatorname{mos}^{7}$ la posibilidad de "constituir, participar en la constitución ni adquirir nuevos entes de cualquier tipología, independientemente de su clasificación sectorial en términos de contabilidad nacional", con la consiguiente prohibición para el resto de

\footnotetext{
$6 \quad$ Según el art. 3 de la LSCA, desarrollar mayoritariamente la actividad en el territorio andaluz es condición para que esta Ley sea aplicable a la cooperativa.

7 En el ámbito andaluz, la denominación correspondiente es de "agencias administrativas", según el art. 34 LAULA.
} 
las entidades públicas locales ${ }^{8}$. Y aún más, sólo se lo permite a aquellos Municipios, Provincias u organismos autónomos que no tengan vigente un plan económico-financiero o su plan de ajuste (aptdo. 1) ${ }^{9}$, pese a lo contradictorio que pueda resultar impedir que los que sí tienen esas medidas en vigor puedan recurrir, gracias a la sociedad de economía mixta, a una la financiación privada para la gestión de sus servicios públicos ${ }^{10}$.

El RSCA admite que sean dos o más las Entidades públicas participantes, lo que podría responder, por ejemplo, a una prestación municipal auxiliada por su correspondiente Diputación Provincial (art. 26.2 y 36 LBRL). No se ajustaría, sin embargo, a una sociedad cooperativa de servicios públicos, en cuanto que sociedad de economía mixta, la que se integrara únicamente por Entes públicos, porque supondría prescindir de la colaboración privada en la gestión del servicio, elemento que hemos considerado esencial y definitorio de la sociedad de economía mixta ${ }^{11}$.

En cuanto a los restantes tipos de socios de la cooperativa de servicios públicos, subrayemos que ellos representan el imprescindible elemento de colaboración privada en una sociedad de economía mixta. El art. 101 RSCA alude a que pueden ser entidades privadas con experiencia en el sector, los usuarios del servicio y los traba-

8 Se trata, como señala SANTIAGO IGLESIAS, de prohibir la "creación de holdings", a través de una norma que no resulta aplicable a las Entidades locales recogidas en el art. 3.2 LBRL, es decir, a las comarcas y equivalentes autonómicos, a las áreas metropolitanas y a las mancomunidades de municipios. ("Empresas Locales" en VELASCO CABALLERO (Dir.): Tratado de Derecho Económico Local, Marcial Pons, 2017: p.162).

$9 \quad$ En el apartado 1 de la Disposición Adicional Novena de la LBRL se lee: "1. Las Entidades locales del artículo 3.1 de esta Ley y los organismos autónomos de ellas dependientes no podrán adquirir, constituir o participar en la constitución, directa o indirectamente, de nuevos organismos, entidades, sociedades, consorcios, fundaciones, unidades y demás entes durante el tiempo de vigencia de su plan económico-financiero o de su plan de ajuste.

Las entidades mencionadas en el párrafo anterior durante el tiempo de vigencia de su plan económico-financiero o de su plan de ajuste no podrán realizar aportaciones patrimoniales ni suscribir ampliaciones de capital de entidades públicas empresariales o de sociedades mercantiles locales que tengan necesidades de financiación. Excepcionalmente las Entidades locales podrán realizar las citadas aportaciones patrimoniales si, en el ejercicio presupuestario inmediato anterior, hubieren cumplido con los objetivos de estabilidad presupuestaria y deuda pública y su período medio de pago a proveedores no supere en más de treinta días el plazo máximo previsto en la normativa de morosidad."

10 Coincido en esta apreciación con SANTIAGO IGLESIAS (2017, p. 163).

11 Sin tener que pronunciarnos aquí sobre la viabilidad de una sociedad cooperativa de otra clase integrada exclusivamente por Entes Públicos, que sirviera de marco de cooperación administrativa, no puede olvidarse que, desde el punto de vista práctico, los entes instrumentales que acogen la cooperación interadministrativa de acuerdo con la Ley 40/2015 y la LBRL, gozan de gran tradición en nuestro Derecho. Eso representa un bagaje jurídico y de experiencia nada despreciable del que hacer uso a la hora de decidir cómo configurar instrumentos de colaboración y cooperación entre Administraciones Públicas. 
jadores $^{12}$. Sería posible diseñar una cooperativa en la que todos los socios facultativos fueran usuarios, o todos trabajadores, o ambos tipos, o empresarios y usuarios, etc. Las combinaciones posibles de tipología de socios potestativos permiten una adaptación a la concreta fórmula de sociedad de economía mixta que se desee articular, así como una prestación del servicio con un mayor o menor grado de participación social.

Mientras que, según el RSCA, la "persona socia trabajadora", ha de ser una persona física, ya que lo que les caracteriza es que su actividad cooperativizada sea su "trabajo personal", no parece tan evidente que la expresión "entidades privadas con experiencia en el sector" haya de referirse exclusivamente a personas jurídicas, aunque eso pudiera ser lo más habitual. Por lo que hace a los usuarios del servicio como eventuales socios, ha de dejarse abierta la posibilidad de que lo sean tanto personas físicas como jurídicas, dependiendo de si el servicio público gestionado admite o no ambos tipos de destinatarios (caso, respectivamente, de la recogida de residuos frente al transporte colectivo urbano, por poner algún ejemplo). No pasa inadvertido que la incorporación de los usuarios como socios de la cooperativa conlleva una interesante faceta de participación social en la prestación del servicio, así como un importante factor de aseguramiento de la demanda, coadyuvante de la sostenibilidad del servicio.

El diseño de la sociedad cooperativa de servicios públicos tendrá que pronunciarse expresamente sobre los concretos tipos de socios que podrán integrarla, así como las condiciones objetivas y no discriminatorias que hayan de ser cumplidas para poder tener la condición de socio. Tales condiciones estarán vinculadas, naturalmente al tipo concreto de servicio público que se desee prestar, pudiéndose, por tanto, tener en cuenta circunstancias de lo más variadas.

Por otro lado al tratar del elemento subjetivo interesa recordar que un relevante sector doctrinal, así como la Comisión Europea, coinciden en apuntar la que la efectiva colaboración entre Administración y el socio privado en el funcionamiento de la sociedad de economía mixta (o de colaboración público-privada ${ }^{13}$.) es uno de sus

\footnotetext{
12 En los tipos de socios estriba principalmente la diferencia de la sociedad cooperativa andaluza con la homónima valenciana. Ésta, además de la entidad pública, solo admite como socios a los usuarios.

13 Véase el documento COM (2004) 327 final, fechado el 30 de abril de 2014.
} 
elementos definidores $^{14}{ }^{15}$. Tanto la parte pública como la privada de estas sociedades han de desempeñar un papel activo, que va más allá de la simple aportación de capital, y que se ha de reflejar en una participación efectiva, en su calidad de socio, en los órganos internos de la sociedad. Esto permite a la Administración no desentenderse de su gestión inmediata (a diferencia de lo que ocurre en una concesión de servicio), aunque materialmente la gestión se deje en manos del socio privado. De ahí puede inferirse que la entidad pública, los usuarios o el empresario no han de integrarse en la cooperativa de servicios públicos como socios inversores, socios inactivos o socios colaboradores, sino como socios comunes, que son los que "realizan plenamente la actividad cooperativizada" (art. 14 LSCA).

Finalmente, para cerrar el comentario del elemento subjetivo de las cooperativas de servicios públicos, ha de mencionarse que la redacción de este estudio coincide con la tramitación parlamentaria de una modificación de la LSCA para que el número mínimo de socios exigible para constituir una cooperativa pase de tres a dos $\operatorname{socios}^{16}$.

Pasemos a analizar el elemento objetivo de la sociedad cooperativa de servicios públicos de una Entidad Local andaluza, esto es, del tipo de actividad que puede desarrollar, que no es otro que la prestación de servicios públicos. El RSCA incorpora ese elemento objetivo como definitorio de esta nueva clase de sociedad, lo que la diferencia, por ejemplo, de una sociedad cooperativa representativa de la iniciativa económica de una Administración Pública, que interviene como un agente más en trá-

14 Así MíGUEZ MACHO (2008): "Las formas de colaboración público-privada en el Derecho español” en REDA, núm 173, p. 163; HERNANDO RYDIGNS (2012): La colaboración público privada. Fórmulas contractuales. Civitas, p. 278; o SANTIAGO IGLESIAS (2010) quien afirma sin ambages que "la gestión conjunta de la sociedad de economía mixta por la Administración y por los socios privados es un elemento esencial de la misma", (Las sociedades de economía mixta como forma de gestión de los servicios públicos locales, Iustel,, p. 64). Muy interesantes resultan las páginas 52 y ss de esta obra, a las que me remito, en donde se repasa la evolución doctrinal al respecto, citando a SOSA WAGNER (La gestión de los servicios públicos locales. Thomson-Civitas, $7^{\mathrm{a}}$ ed, 2008, p. 341) y a SANTAMARÍA PASTOR (Principios de Derecho Administrativo General, tomo II, $2^{\text {a }}$ ed, Iustel, 2009, p. 334) entre los autores que postulan la implicación de la Administración como característica definitoria de la sociedad de economía mixta; mientras que LLISET BORRELL (La actividad empresarial de los Entes Locales, El Consultor de los Ayuntamientos y de los Juzgados, 1990, P. 147) o PRIETO GONZÁLEZ (Las empresas mixtas locales, Montecorvo, 1996, p. 44) mantienen la postura contraria.

15 La Comisión Europea, en su "Comunicación interpretativa relativa a la aplicación del Derecho comunitario en materia de contratación pública y concesiones a la colaboración público-privada institucionalizada (CPPI)" (2008/C 91/02), dice que "La aportación privada a los trabajos de la CPPI [colaboración público-privada institucionalizada], además de la contribución al capital u otros activos, consiste en la participación activa en la ejecución de las tareas confiadas a la entidad de capital mixto y/o la gestión de dicha entidad. En cambio, la simple aportación de fondos por un inversor privado a una empresa pública no constituye una CPPI."

16 Consúltese el Boletín Oficial del Parlamento de Andalucía de 4 octubre de 2017, en el que se publica el proyecto de Ley para la modificación parcial de la LSCA. 
fico jurídico en un contexto de libre mercado y competencia. Esto último es posible con la legislación estatal de cooperativas y cualquiera otra autonómica, pues todas permiten que una persona jurídico-pública se integre como socio en una sociedad cooperativa, con independencia de la clase de que se trate. Pero solo la andaluza y la valenciana tienen una clase específica para la prestación de servicios públicos. Más allá de la delimitación negativa resultante de oponer "servicio público" a "iniciativa económica administración", acotar las actividades a las que se refiere la expresión "servicios públicos" no está exento de dificultad, entre otras cosas porque ni siquiera el legislador la ha manejado con el rigor que sería deseable esta destinción ${ }^{17}$. Además, la categoría de "servicio público", en su evolución ${ }^{18}$, está siendo arrinconada por otras surgidas al abrigo del derecho europeo, sustancialmente la de "servicios de interés general". Esa es la que emplea la LAULA, que en su art. 26.1 dice que "(S)on servicios locales de interés general los que prestan o regulan y garantizan las entidades locales en el ámbito de sus competencias y bajo su responsabilidad, así como las actividades y prestaciones que realizan a favor de la ciudadanía orientadas a hacer efectivos los principios rectores de las políticas públicas contenidos en el Estatuto de Autonomía para Andalucía."

Lo anterior sitúa el objeto de las sociedades cooperativas de servicios públicos de las Entidades locales andaluzas entre las actividades de servicio de interés general que, a su vez, formen parte del elenco de competencias del socio Entidad local, de conformidad con una norma con rango de Ley, básica o autonómica, general o sectorial ${ }^{19}$. Puede tratarse de competencias cuya prestación se haya reservado monopolísticamente a la Entidad local por la LBRL (art. 26.2,) o en la LAULA (art. 32) o en la legislación sectorial de aplicación ${ }^{20}$; o actividades no reservadas; pueden ser actividades de prestación facultativa o de prestación obligatoria, a veces

17 En este sentido, MONTOYA MARTIN (2012) "Los servicios y la iniciativa económica locales" en RIVERO YSERN (Dir.): Derecho Local de Andalucía. Iustel, p. 159.

18 ORTEGA BERNARDO (2017): "Servicios públicos e iniciativa económica local" en VELASCO CABALLERO (Dir.): Tratado de Derecho económico local. Marcial Pons, p.76., en una apretada síntesis histórica diferencia tres acepciones de la expresión "servicio público": 1) actividad reservada exclusivamente a la Administración (VILLAR PALASÍ, GARCÍA DE ENTERRRÍA, GARCÍA TREVIJANO); 2) actividad que sirve al interés general, realizada por la Administración o por los particulares -actividades reguladas(MARTIN REBOLLO, BASOLS COMA, ARIÑO ORTIZ, etc); 3) actividad prestacional administrativa, gestionada directa o indirectamente (LÓPEZ PELLICER, PARADA VÁZQUEZ, BERMEJO VERA)

19 Sobre las clases de competencias locales, véase, por todos, el trabajo de TOSCANO GIL (2014):"El nuevo sistema de competencias municipales tras la Ley de racionalización y sostenibilidad de la administración local: competencias propias y competencias distintas de las propias y de las atribuidas por delegación” en REDA núm. 165.

${ }_{20}$ Recordemos que para efectuar tal reserva, además de que el pronunciamiento de reserva tenga lugar mediante norma con rango de Ley, se requiere que proceda la calificación del servicio como un "servicio esencial", por apreciarse en él de forma excepcional un especial interés general. 
en función del volumen de su población (art. 26.1 LBRL) y otras con independencia de ello (art. 31 LAULA) ${ }^{21}$.

Salvo cuando sean objeto de reserva monopolística a favor de la Entidad local, los servicios locales de interés general se podrán prestar en régimen de mercado (esto es, compitiendo con la iniciativa privada) pero, si fuera necesario, porque, por ejemplo, la oferta del mercado no fuera satisfactoria, podrían introducirse excepciones sobre tal régimen. Y así, sobre la base de los intereses generales subyacentes, y al amparo del art. 106.2 TFUE, sería admisible que los servicios locales de interés general se llevaran a cabo en régimen de servicio público, o sea alterando las reglas del libre mercado y de la competencia. Por tanto, en la medida en que sea necesario y proporcionado al objetivo de garantizar el acceso de la población en las condiciones del art. 27 LAULA $^{22}$, las cooperativas de servicio público podrían quedar habilitadas a actuar con medidas tales como precios inferiores a los de mercado (art. 44.2 LHL) ${ }^{23}$, u otras que pudieran afectar a la libre competencia (art. 44 Ley de Defensa de la Competencia) ${ }^{24}$, o teniendo que satisfacer obligaciones o misiones de servicio público $^{25}$.

El objeto de las cooperativas de servicios públicos termina de perfilarse añadiendo dos límites que derivan de su condición de sociedades de economía mixta y de la fórmula (contractual) de gestión indirecta de servicios públicos. El primero es un límite negativo: sus actividades no podrán implicar ejercicio de la autoridad inherente a los poderes públicos (art. 85.2 LBRL, art. 33.5 LAULA, arts. 17 y 284 LCSP). El art. 101 RSCA repite la prohibición y la concreta con los ejemplos de los servicios de "orden público y protección civil". El segundo límite, por el contrario, es positivo: sus actividades han de ser susceptibles de explotación económica (art. 284 LCSP).

$21 \quad$ En este sentido, resulta muy interesante la determinación de actividades objeto del servicio público local frente a las actividades objeto de la iniciativa económica local que realiza ORTEGA BERNARDO (2017: p. 93 y ss). regularidad.

${ }^{22}$ Recoge este artículo las tradicionales condiciones de universalidad, igualdad, continuidad y

23 En este sentido, el art. 44.2 de la Ley de Haciendas Locales (aprobada por Real Decreto Legislativo 2/2004, de 5 de marzo) prevé que "Cuando existan razones sociales, benéficas, culturales o de interés público que así lo aconsejen, la entidad podrá fijar precios públicos por debajo del límite previsto en el apartado anterior", esto es, por debajo del coste del servicio o actividad.

24 Este artículo de la Ley 15/2007, de 3 de julio, de Defensa de la Competencia ampara las restricciones a la libre competencia que establezcan las Administraciones Públicas al amparo implícito de una Ley. Su tenor literal es el siguiente: "1. Sin perjuicio de la eventual aplicación de las disposiciones comunitarias en materia de defensa de la competencia, las prohibiciones del presente capítulo no se aplicarán a las conductas que resulten de la aplicación de una ley."

25 MONTOYA MARTÍN (2012: 175), ORTEGA BERNARDO (2017: 90 y ss). 
Pasando a otra cuestión, interesa verificar si el carácter no lucrativo es una nota distintiva de las sociedades cooperativas de servicios públicos. La LSCA sólo se pronuncia sobre este aspecto a propósito de las cooperativas de interés social (art. 94), a las que deja libertad para determinarlo en sus Estatutos ${ }^{26}$. El art. $80 \mathrm{RSCA}^{27}$, sin embargo, sí aborda la cuestión para las cooperativas especiales (entre las que figuran las cooperativas de servicios públicos). Lo hace remitiéndose a las previsiones que en su art. 80.1 se fijan para las cooperativas de trabajo no lucrativas (RSCA), que han de recoger en su régimen económico estatutario, las siguientes condiciones:

“a) La imposibilidad de que las aportaciones al capital social devenguen un interés superior al legal del dinero, sin perjuicio de su posible actualización.

b) La retribución de las personas socias trabajadoras y de los trabajadores y trabajadoras por cuenta ajena no excederán del ciento cincuenta por ciento de la que les correspondería en virtud del convenio colectivo u otra disposición laboral aplicable en la zona.

c) Los excedentes o beneficios que puedan generarse en un ejercicio económico, en ningún caso se repartirán entre las personas socias e inversoras, en su caso, destinándose a la consolidación de la entidad y a la creación de empleo, una vez cubiertos los porcentajes relativos a los fondos obligatorios, que tendrán carácter irrepartible".

Para que una cooperativa de servicios públicos no tenga ánimo de lucro, además de indicarlo en la definición estatutaria de su objeto social, el estatuto debería hacer suyas en el apartado sobre el régimen económico las condiciones arriba transcritas, aunque se le permite modularlas "en lo que les sea de aplicación". Así, por ejemplo, si una cooperativa de servicios públicos se configurara sin socios trabajadores, va de suyo que podría prescindir de la condición limitativa de la cuantía de su remuneración. Más discutible resulta que pudiera eludirse la prohibición de reparto de excedentes o beneficios entre los socios, cuando entre ellos existiera un empresario, y la cooperativa hubiera de asumir el riesgo económico de la actividad económica en que consista el servicio público.

26 Comenta MORILLAS JARRILLO que esto es una peculiaridad de la legislación andaluza de cooperativas, pues en la mayoría de las legislaciones autonómicas carecen de ánimo de lucro ex lege ("Concepto y clases de cooperativas" en PEINADO GARCÍA (Dir.): tratado de Derecho de Cooperativas. Vol. I. Tirant lo Blanch, p.134.

${ }_{27}$ Para un comentario de este precepto, véase a MORILLAS JARRILLO: "Tipología y clasificación de las sociedades cooperativas andaluzas" en AA.VV.: Retos y oportunidades de las sociedades cooperativas andaluzas ante su nuevo marco legal. Dickinson, 2017, p. 55 y ss. 
Para terminar esta caracterización, refirámonos al régimen jurídico de las cooperativas de servicios públicos. Antes de poder constituirla, la entidad local promotora tendrá que haber aprobado la Ordenanza reguladora del servicio, asumir efectivamente su prestación (en caso de monopolio, mediante expediente de municipalización), y la fórmula de gestión indirecta a través de esta clase especial de cooperativa, todo ello de acuerdo con la legislación básica y autonómica andaluza de régimen local. Seleccionados los socios (ver epígrafe siguiente), la constitución propiamente dicha de la cooperativa, y todo su régimen de organización y funcionamiento se regirá por Derecho privado, fundamentalmente por la LSCA, el RSCA. No obstante, existen aspectos de su régimen jurídico en donde el Derecho Administrativo queda implicado a causa de la incorporación de un ente público y a la asignación a la sociedad del encargo de gestionar un servicio público. A ellos dedicamos el resto de este estudio.

\section{IMPACTO DE LA LEGISLACIÓN DE CONTRATACIÓN PÚBLI- CA EN LA CONSTITUGIÓN DE UNA COOPERATIVA DE SER- VICIOS PÚBLICOS}

El régimen de las cooperativas de servicios públicos, en cuanto que sociedades de economía mixta, queda afectado por la legislación de contratación pública en los siguientes cuatro aspectos: a) la necesidad de un contrato entre la entidad pública (que simultanea la condición de titular del servicio público y de socio cooperativo); b) el tipo de contrato que debe celebrarse; c) el procedimiento de selección y de adjudicación del contrato; y d) por último, la duración de la cooperativa. Veamos cada uno de ellos.

En primer lugar, la puesta en funcionamiento de una cooperativa de servicios públicos no sólo implica crearla como nuevo sujeto jurídico. Requiere, además, que la entidad pública externalice el servicio y asigne a la cooperativa el título jurídico habilitante (contrato administrativo ${ }^{28}$ ) para la realización de la actividad económica de interés general en régimen de servicio público. No basta, pues, la presencia entre los socios de la cooperativa de una entidad pública para que la sociedad quede habilitada para la prestación del servicio. Para esto último es imprescindible, entre otros requisitos, que además de existir la cooperativa donde confluya la colaboración público-privada, ésta ostente el título jurídico contractual que le permita llevar a cabo tal actividad, obtenido conforme a las reglas y procedimientos previstos en la legislación contractual. De ahí que el art. 182 del Reglamento General de la Ley de

28 Las restricciones del elemento subjetivo de estas cooperativas, comentadas en el punto II, comportan que el contrato sea administrativo. 
contratos de las Administraciones Públicas ${ }^{29}$, establezca que "En los contratos de gestión de servicios públicos la sociedad de economía mixta figurará como contratante con la Administración, correspondiéndole los derechos y obligaciones propios del concesionario de servicios públicos."

En segundo lugar, hay que dedicar atención al tipo de contrato que debe celebrarse con la cooperativa de servicios públicos. Como es sabido, la LCSP ha optado por la eliminación del contrato de gestión de servicios públicos ${ }^{30}$, para sustituirlo por el contrato de concesión de servicios o el contrato de servicios, según, respectivamente, el riesgo de la operación se traslade o no al contratista, independientemente de que la actividad que éste realice constituya un servicio público. En este contexto, el groso de la derogada DA 29 ${ }^{\text {a }}$ LCSP de 2011 se traslada a la DA $22^{\text {a }}$ LCSP, donde pervive la sociedad de economía mixta, pero restringiendo su posible objeto: ahora no permite que la sociedad sea contratista de un contrato de servicio, sino únicamente de concesión de servicios, aunque aquél también puede ser un vehículo para la gestión indirecta de servicios públicos. Esta inexplicable limitación, repercute negativamente en el posible juego de la sociedad cooperativa de servicios públicos, puesto que su ámbito de acción se verá igualmente constreñido.

En tercer lugar, la legislación de contratos repercute igualmente en el procedimiento para la selección de los socios con los que proceder a la constitución de una sociedad cooperativa de servicios públicos. La LAULA, al ocuparse en su art 43.2 de las Sociedades de economía mixta, determina que "(e)n todo caso, el proceso de constitución de estas sociedades tiene que asegurar la libre concurrencia y la igualdad de oportunidades del capital privado, por lo que la selección del socio privado estará sujeta a los procedimientos de concurrencia que resulten de aplicación según la legislación de contratos del sector público." La norma es taxativa en cuanto a la necesidad de seleccionar a quienes vayan a ser socios de la cooperativa mediante un procedimiento de pública concurrencia competitiva en igualdad de condiciones.

Este requisito está previsto igualmente en el art. 104 TRRL, donde, en este contexto, puede leerse que “(e)n todo caso, deberá determinarse si la participación de los particulares ha de obtenerse únicamente por suscripción de acciones, participaciones o aportaciones de la empresa que se constituya o previo concurso en que los concursantes formulen propuestas respecto a la cooperación municipal y a la particular en la futura Sociedad, fijando el modo de constituir el capital social y la partici-

29 Aprobado por el Real Decreto 1098/2001, de 12 de octubre.

30 La decisión del legislador suscita numerosas e interesantes cuestiones jurídicas en las que no podemos entrar y que expone HERNÁNDEZ GONZÁLEZ, F. (2016): "La controvertida supresión del contrato de gestión de servicios públicos" en Revista EL CRONISTA del Estado Social y Democrático de Derecho núm. 60. 
pación que se reserve la Entidad local en la dirección de la Sociedad y en sus posibles beneficios o pérdidas y demás particulares que figuren en la convocatoria (...)".

Se diría, pues, que son dos los procedimientos de selección de los socios de la cooperativa participada por una Entidad pública local: uno, la suscripción pública de participaciones en el capital social por quienes reúnan las condiciones objetivas para poder ser socio de la cooperativa; y otro el concurso de iniciativas en el que los concursantes formulen propuestas respecto a la futura sociedad (modo de constituir el capital social, participación reservada a la Entidad local en la dirección, etc. $)^{31}$. Sin embargo, en la práctica, sólo tiene cabida la segunda fórmula, como se va a exponer.

La adjudicación del contrato público (de concesión de servicios) requiere, de acuerdo con la LCSP, de un procedimiento de selección pública, competitiva y no discriminatoria, a resultas del cual el contrato se adjudique a quien presente la oferta más ventajosa. Por ello, no es jurídicamente viable la adjudicación directa del contrato público a una sociedad de economía mixta que haya sido previamente constituida entre la Administración y socios privados elegidos de cualquier otro modo. Igualmente inválido resultaría que la Entidad local eligiera sin más una sociedad cooperativa preexistente a la que incorporarse como socio, para luego adjudicarle sin licitación pública el contrato público. Tampoco valdría, por discriminatoria, una licitación pública del contrato en donde la posibilidad de presentar ofertas se restringiera a sociedades cooperativas, salvedad hecha de las reservas legalmente previstas (art. 132, DA $4^{\mathrm{a}}$ y $48^{\mathrm{a}}$ LCSP).

Los supuestos de adjudicación directa propiamente dicha previstos en la LCSP son muy escasos y se reducen a los contratos menores, y a los encargos a medios propios (art. 32 LCSP). Con ninguno de estos dos supuestos de adjudicación directa se podría válidamente constituir en contratista de gestión de servicios públicos a una sociedad cooperativa mixta previamente existente. El primer caso, el contrato menor, habría que descartarlo en la práctica porque el art. 118 LCSP no contempla la figura del contrato menor para las concesiones de obras y de servicios, que son los dos contratos reservados por la DA $22^{\text {a }}$ para las sociedades de economía mixta. El segundo supuesto para la adjudicación directa está previsto para cuando el contratista es medio propio del Ente contratante. Este tampoco se aviene con la realidad de las sociedades cooperativas de servicios público como sociedad de economía mixta, porque los requisitos para que un Ente merezca la consideración de medio propio (y pueda ser objeto de adjudicaciones directas de contratos o encargos) del art. 32.2

31 Podría pensarse que el carácter personalista de las sociedades cooperativas se aviene mejor a la fórmula del concurso de iniciativas, pues permite que la adjudicación tenga en cuenta la participación privada en la actividad de la cooperativa y el dato de tener en común intereses o necesidades socioeconómicas, etc. 
LCSP impiden que puedan serlo sociedades de economía mixta, al exigir que si se trata de entes de personalidad jurídico-privada, como son las sociedades, la totalidad de su capital tiene que ser de titularidad pública. ${ }^{32}$.

Por tanto, si un encargo de gestionar un servicio público se realiza por una Entidad local a quien no sea "medio propio o servicio técnico", como ocurre con una Sociedad Cooperativa de Servicios Públicos que tenga tanto socios privados como socios públicos, es condición ineludible de validez que ese encargo sea el resultado de un procedimiento de licitación pública, de los regulados en la legislación contractual.

La importancia de esta exigencia sobre el proceso de constitución de la sociedad cooperativa (en cuanto que sociedad de economía mixta) estriba en que las opciones para su efectiva constitución quedan en la realidad fuertemente reducidas porque, como bien se ha reconocido por la propia Comisión Europea ${ }^{33}$, tener que pasar por una doble licitación pública, una primera para seleccionar a los socios privados y otra posterior para adjudicar el contrato de gestión de servicios públicos, "no resulta muy práctico". Piénsese que en el segundo procedimiento, a la hora de adjudicar el contrato (y conseguir el título habilitante para desarrollar la actividad en régimen de servicio público), ninguna ventaja podrá irrogarse la sociedad cooperativa por el simple dato de su forma jurídica (salvo caso de empate) ${ }^{34}$ o de la integración de la Entidad local en la propia sociedad, so pena de incurrir en discriminación. En definitiva, como bien destaca la Comisión, la doble licitación no resulta viable en la vida real. Es evidente lo desincentivador de una doble licitación para la colaboración público-privada, tanto por la dilación inherente al desarrollo de dichos procedimientos como por la incertidumbre jurídica que existiría en cuanto a la adjudicación de la concesión contractual a la sociedad de economía mixta formada con el socio privado previamente seleccionado.

Buscando una solución a la barrera jurídica que representa la doble licitación, en su célebre Comunicación interpretativa relativa a la aplicación del Derecho comunitario en materia de contratación pública y concesiones a la colaboración público-privada institucionalizada ${ }^{35}$, la Comisión sugirió sintetizar ambos procedimientos en uno que, respetando el carácter público, transparente y competitivo, pudiera servir para seleccionar el socio privado de una sociedad mixta y adjudicarle el contrato público. Con

32 En el asunto Stadt Halle (Asunto G-26/03) el TJCE se estableció la incompatibilidad entre el concepto de medio propio y la participación, si quiera minoritaria, de empresas privadas en dicho sujeto.

33 Comunicación interpretativa de la Comisión relativa a la aplicación del Derecho comunitario en materia de contratación pública y concesiones a la colaboración público-privada institucionalizada

34 De acuerdo con el art. 116.2 LSCA "Las sociedades cooperativas gozarán de preferencia, en caso de empate, en la adjudicación de contratos de las administraciones públicas andaluzas".

35 Véase su apartado 2.2 in fine. 
ello la viabilidad de la operación quedaría garantizada, pues se salvaguardarían los principios fundamentales de los arts. 43 y 49 del Tratado CE, así, como en su caso, de las Directivas sobre contratación pública ${ }^{36}$.

La síntesis procedimental cuenta con respaldo en la doctrina jurisprudencial del Tribunal de Justicia de la Unión Europea ${ }^{37}$, que ha admitido que la adjudicación directa a la empresa de economía mixta (léase cooperativa de servicios públicos) es válida siempre y cuando la selección del socio se haga mediante licitación con pública concurrencia y en condiciones de no discriminación e igualdad de trato, en la que se verifique no sólo la capacidad de aportar el capital sino también los requisitos financieros, técnicos, operativos y de gestión relativos al servicio que deba prestarse y de las características de la oferta en cuanto a las prestaciones que deban realizarse.

En la legislación de contratación pública se ha recogido este procedimiento posibilidad en la DA $22^{\text {a }}$ LCSP), donde se afirma que "las concesiones de obras y de servicios podrán adjudicarse directamente a una sociedad de economía mixta (...), siempre que la elección del socio privado se haya efectuado de conformidad con las normas establecidas en esta Ley para la adjudicación del contrato cuya ejecución constituya su objeto, y siempre que no se introduzcan modificaciones en el objeto y las condiciones del contrato que se tuvieron en cuenta en la selección del socio privado".

En resumen, el elenco de requisitos procedimentales derivados de la legislación de contratos para poder proceder a la constitución de una sociedad de economía mixta con forma cooperativa son:

- selección de los socios privados mediante procedimiento de pública y libre concurrencia no discriminatoria.

$36 \quad$ Si bien el contrato de gestión de servicios públicos no resultaba afectado por las Directiva 18/2004 sobre coordinación de los procedimientos de adjudicación de los contratos públicos de obras, de suministro y de servicios, su objeto sí se recoge en los que regula de la Directiva 2014/23/UE del relativa a la adjudicación de contratos de concesión.

37 Por todas, su Sentencia de 15 de octubre de 2009 (asunto C-196/08, caso Acoset) en que se resuelve la cuestión prejudicial planteada por un órgano jurisdiccional italiano planteada en los siguientes términos “ ¿Es compatible con el Derecho comunitario, en particular con las obligaciones de transparencia y de libre competencia recogidas en los artículos 43, 49 y 86 del Tratado, un modelo de sociedad de economía mixta, creada únicamente para la prestación de un servicio público de naturaleza industrial y con objeto social exclusivo, que sea adjudicataria directa del servicio de que se trata y en la que el socio privado, de carácter "industrial" y "operativo", sea seleccionado mediante un procedimiento de licitación pública, previa verificación tanto de los requisitos financieros y técnicos como de los requisitos propiamente operativos y de gestión relativos al servicio que debe proporcionarse y a las prestaciones específicas que han de ejecutarse?" Para un comentario de esta cuestión, ver el trabajo de GALLEGO CÓRCOLES: "La gestión de servicios públicos mediante sociedades de economía mixta en la jurisprudencia europea (I) y (II) en Contratación administrativa práctica: revista de la contratación administrativa y de los contratistas, $\mathrm{n}^{\circ} 105$ y 106 respectivamente, 2011. 
- usar para la selección de socios privados cualquiera de los procedimientos que, de conformidad con la LCSP, permita la adjudicación del contrato de concesión de servicios, a saber, procedimiento abierto, restringido, negociado o diálogo competitivo.

- adjudicar el contrato público habilitante para la prestación del servicio público de forma directa a la sociedad cooperativa de servicios públicos que tienen obligación de constituir los socios seleccionados junto con la Entidad local.

- plena coincidencia entre el objeto y condiciones que se tienen en cuenta para la selección del socio, por un lado, y el objeto y condiciones del contrato de concesión de servicio o servicio que se adjudique directamente a la sociedad de economía mixta, por otro. De lo contrario, se incurriría en una modificación sustancial del contrato que obligaría, como tiene declarado el Tribunal de Justicia ${ }^{38}$, a una nueva licitación, dando al traste con las ventajas de la solución procedimental aquí comentada.

En cuarto lugar, como corolario de lo anterior, la sociedad cooperativa de servicios públicos perderá su objeto y su razón de ser en el momento de la extinción contractual. La duración finita del contrato administrativo de concesión de servi$\operatorname{cios}^{39}$, contagia a la propia sociedad. Sin embargo, si la actividad pudiera realizarse en régimen de mercado, la cooperativa podría pervivir, aunque ya sin beneficiarse de ninguna medida de exclusión de las reglas de libre mercado y competencia, y siempre que cambiara de clase de cooperativa, abandonando la de cooperativa de servicios públicos.

Para cerrar este punto, hagamos referencia a los elementos que deben ser objeto de publicidad en el anuncio de la licitación pública para la selección de socios y adjudicación del contrato de concesión de servicio. El art. 285 LCSP fija el contenido mínimo de los pliegos del contrato de concesión de servicio, aludiendo al objeto del contrato, condiciones de prestación del servicio y tarifas de usuarios, condiciones de solvencia del contratista, la distribución de riesgo y previsiones sobre cesión del contrato. Siguiendo el buen criterio de SANTIAGO IGLESIAS ${ }^{40}$, el anuncio de licitación o los pliegos de condiciones también deberían cubrir los Estatutos de la futura sociedad, la duración del contrato, y el resto de los elementos por los que se vaya a

$38 \quad$ En la Sentencia Acoset, ya citada, el Tribunal desciende a recordar que "una sociedad de capital mixto, público y privado, como la que se contempla el litigio principal, debe conservar el mismo objeto social todo el tiempo que dure la concesión, y que toda modificación sustancial del contrato obligaría a proceder a una licitación (véase en este sentido la sentencia de 19 de junio de 2008, pressetext Nachrichtenagentur GmbH, C-454/06, Rec. p. I-4401, apartado 34)"

39 La LCSP afirma que los contratos de concesión de servicios "tendrán un plazo de duración limitado, el cual se calculará en función de las obras y de los servicios que constituyan su objeto", y como duración máxima, según los casos, fija cuarenta, veinticinco y diez años (art. 29.6).

40 Las sociedades... ob. cit, p. 192 y 193. 
regir tanto la relación contractual entre la entidad adjudicadora y los socios privados, como la relación entre la Entidad pública y la futura entidad de economía mixta que se creará. Habría también que añadir, a la vista del concreto servicio público de que se trate, la enumeración de los requisitos de solvencia técnica, profesional, económica y financiera que haya de reunir la sociedad cooperativa, lo que puede repercutir en los que, a su vez, sean exigibles para alcanzar la condición de socio (en sus distintas modalidades) de la cooperativa. No estaría de más que también figurara el tiempo que se otorga a los socios para constituir la sociedad y en que se pudiera adjudicar definitivamente el contrato público.

\section{A. Vigencia y modulación del principio de libre adhesión y baja voluntaria en las cooperativas de servicios públicos}

Entre los principios informadores de la constitución y funcionamiento de las cooperativas figura en primer lugar el de "libre adhesión y baja voluntaria de los socios ${ }^{41}$ (art. 4 LSCA). Este principio quiere expresar la idea de que las cooperativas son organizaciones voluntarias, abiertas a todas las personas capaces de utilizar sus servicios y dispuestas a aceptar las responsabilidades de ser socio sin discriminación de sexo, social, racial, política o religiosa ${ }^{42}$. El alta y baja de socios durante la existencia de la sociedad cooperativa es algo que se prevé más que como algo natural, como un principio inspirador del movimiento cooperativo. Por ello, de acuerdo con la legislación cooperativa, se puede adquirir la condición de socio en el momento de la constitución de la sociedad, pero también más adelante a través de la incorporación de nuevas personas a la sociedad cooperativa; y de forma semejante, la baja voluntaria permite al socio dejar de serlo.

Conociendo las peculiaridades procedimentales para la selección de socios para la constitución de sociedades cooperativas de servicios públicos, surge inevitablemente la pregunta de si puede tener vigencia tal principio, y en su caso, cómo se manifiesta. Para ello bueno será diferenciar la respuesta en función del momento en que se pretenda realizar los cambios de socios de la cooperativa.

${ }^{41}$ Véase al respecto el estudio de VARGAS VASSEROT, C: "El principio cooperativo de puertas abiertas (adhesión voluntaria y abierta). Tópico o realidad en la legislación y en la práctica societaria” en CIRIEC - España. Revista jurídica de economía social y cooperativa, n 27 2015, donde se abordan las diferencias estructurales entre distintos tipos de cooperativas, para llegar a la conclusión de que el principio de libre adhesión no rige en ellas con igual intensidad y que su efectividad depende, en gran medida, del particular desarrollo estatutario de cada entidad.

42. Así lo expresa la Declaración sobre la Identidad Cooperativa de la Alianza Cooperativa Internacional de 23 de septiembre de 1995 (conocida también como Declaración de Manchester). Al respecto interesa PAZ CANALEJO (1995) "Principios cooperativos y prácticas societarias de la cooperación" en REVESCO n 61, p. 20 y MARTÍNEZ CHARTERINA (1995): "Los valores y principios cooperativos" en REVESCO n 61. 
En cuanto al momento de la constitución societaria, el hecho de haber tenido que seleccionar a los socios a través de un procedimiento de pública y libre concurencia competitiva no discriminatoria implica la imposibilidad jurídica de que en el momento de constituir la cooperativa otros sujetos no seleccionados de esta forma se agreguen a la sociedad ${ }^{43}$. De otra manera se burlaría abiertamente el resultado de dicha selección.

En un segundo momento, una vez constituida la sociedad cooperativa de servicio público con los socios elegidos mediante licitación pública, y perfeccionado con ella el contrato para la prestación del servicio público ¿es admisible la baja voluntaria de cualquiera de ellos? ¿Qué consecuencias jurídicas tendría? ¿Sería legal proceder a la admisión de nuevos socios?

La cuestión de la mutabilidad de los socios en el concreto caso de la sociedad cooperativa de servicios públicos no se aborda directamente en la legislación de cooperativas. El RSCA al tratar de este tipo de cooperativas nada especifica sobre requisitos o límites a la adhesión o baja voluntaria de socios durante la vida de la cooperativa, ni menos aún de sus consecuencias para la sociedad. Tampoco lo hacía la LCSP de 2011, que sí se preocupaba de la cesión contractual de los contratos administrativos, de la absorción o de la escisión empresas que afecten al contratista, pero no de si los socios de una persona jurídica que sea contratista, podían modificarse. La nueva LCSP viene a llenar este vacío en su art. 214, donde se establece que "cuando los pliegos prevean que los licitadores que resulten adjudicatarios constituyan una sociedad específicamente para la ejecución del contrato, establecerán la posibilidad de cesión de las participaciones de esa sociedad; así como el supuesto en que, por implicar un cambio de control sobre el contratista, esa cesión de participaciones deba ser equiparada a una cesión contractual a los efectos de su autorización de acuerdo con lo previsto en el presente artículo. Los pliegos podrán prever mecanismos de control de la cesión de participaciones que no impliquen un cambio de control en supuestos que estén suficientemente justificados". Al amparo de esta previsión, y de la concordante

43 En este sentido, aunque no se refiere específicamente a cooperativas, SANTIAGO IGLESIAS afirma con toda rotundidad que como las personas que se convertirán en socios de la futura sociedad de economía mixta han sido seleccionadas mediante un procedimiento recogido en la LCSP, "no procede el que, ahora, en la fase de constitución jurídico-mercantil, antes del otorgamiento de la escritura de constitución, actuando la Administración y el socio privado, debidamente seleccionado como promotores, se proceda a la admisión de la participación de nuevos socios privados que no han sido seleccionados a través del correspondiente procedimiento administrativo" (2010: p. 229). Incluso añade esta autora una reflexión sobre la innecesariedad de proceder, tratándose de una sociedad de economía mixta, a ofrecer públicamente las acciones de la sociedad (está pensando en sociedades de capital) en un procedimiento de fundación sucesiva; y lo justifica en que el socio seleccionado habrá cubierto suficientemente las necesidades de financiación de la sociedad con la suscripción de la proporción de capital social que le corresponda en virtud del contrato. 
de su art. 285 para contratos de concesión de servicio, puede materializarse el principio cooperativo de libre adhesión y baja voluntaria en las cooperativas andaluzas de servicios públicos, donde la idea misma de integrar como socios a trabajadores, o a los propios usuarios provoca la necesidad de un sistema que atienda a los cambios societarios (por ejemplo, sujetos que desean causar baja por no necesitar o desear usar el servicio, y otros con el deseo contrario).

Lo anterior habrá de articularse debidamente con la LSCA y su regulación del procedimiento y requisitos para poder convertirse en socio cooperativo y para causar baja voluntaria, que deja un importante espacio normativo a los Estatutos de la sociedad cooperativa, para que incorporen requisitos y condiciones al respecto, y funcionar como soporte para la lícita negativa por parte de la Cooperativa a acoger nuevos socios. Según el art. 18.4 LSCA "(l)a denegación expresa de la solicitud de admisión habrá de estar motivada y vinculada a la existencia de una causa justificada dispuesta en los Estatutos sociales o en una disposición normativa, o a la imposibilidad técnica derivada de las condiciones económico-financieras, organizativas o tecnológicas de la entidad". Queda claro, por tanto, que el principio de "libre adhesión de socios" no implica un derecho subjetivo incondicionado del solicitante a incorporarse a la sociedad cooperativa, sino solo un derecho a solicitar la admisión ${ }^{44}$. Diferente es el derecho a la baja voluntaria, que, según el art. 23 LSCA, sí se configura como derecho subjetivo, aunque puede estar sujeto a previsiones estatutarias de permanencia mínima o de ejercerse al final del ejercicio económico, y está sujeto a un plazo de preaviso cuyo incumplimiento no impide la baja, pero obliga a indemnizar eventuales daños y perjuicios a la sociedad ${ }^{45}$.

Dada la diferente naturaleza del alta y la baja voluntaria, conviene diferenciar también su régimen. Comenzando por la baja voluntaria habría que distinguir en función de la actividad cooperativizada y del tipo de socio, los supuestos en que su ejercicio pudiera implicar la extinción del contrato público, con independencia de que la sociedad cooperativa pudiera pervivir previa mutación de clase. De este modo, por ejemplo, entre las causas de resolución incorporadas al contrato público habría de figurar el ejercicio por el socio público de su derecho de baja voluntaria, en consonancia con lo sostenido en el epígrafe II.

44 LASSALETTA GARCÍA explica que "el carácter abierto sobre el que se construye el acceso a la condición de socio en modo alguno lleva implícito un «derecho subjetivo a la admisión» en la cooperativa, sino sólo un «derecho subjetivo a solicitarla». Véase su trabajo "Tipos de socios y otras formas de participación social” en PEINADO GRACIA (Dir.): Tratado ob. cit, p.221.

45 Escapan de este trabajo otras consecuencias de la baja, entre las que destaca el derecho de reembolso, tratado monográficamente por VIGUERAS REVUELTA (2015): El derecho de reembolso en las sociedades cooperativas. Tirant lo Blanch. 
Por lo que hace a la incorporación de nuevos socios, el art. 18.4 LCSA determina que los límites a la libre adhesión serán los especificados en los Estatutos sociales; los derivados de disposiciones normativas aplicables (por ejemplo, los límites estructurales del capital social), y los que puedan subsumirse en la cláusula de ese mismo artículo referida a la imposibilidad técnica por condiciones económico-financieras, organizativas o tecnológicas de la entidad. En la medida en que esa incorporación represente una modificación contractual, también debería estar prefigurada en los pliegos que rigen la licitación del contrato público. Si se hubiera diseñado la cooperativa con socios usuarios, las posibilidades de alta de nuevos socios habrán de recogerse en los Estatutos atendiendo al mantenimiento de la estructura del capital de la sociedad y a otros factores relacionados con las características del servicio público en cuestión (siempre aplicadas de forma no discriminatoria), y con la máxima publicidad y transparencia en el procedimiento de admisión, especialmente si se sujetara a plazos, condiciones, etc. Otro tanto cabría decir para los socios trabajadores, si bien subrayando, sobre todo, los necesarios requisitos de solvencia profesional, que hubieran de ser exigidos en función del tipo de actividad que hubieran de desempeñar en la ejecución del contrato público.

Por último, habría que plantear la viabilidad de sustituir un socio por otro de idéntica clase. No sería factible para el socio Entidad pública, habida cuenta de que en la sociedad debe integrarse como Entidad local la que sea titular de la competencia para prestar el servicio público en cuestión en el ámbito geográfico de que se trate. En cambio para el resto de los socios, y especialmente para el socio empresario, sí podría considerarse en los términos de la LCSP.

\section{PECULIARIDADES DEL GAPITAL SOCIAL DE LAS GOOPERA- TIVAS DE SERVICIOS PÚBLICOS}

Como ocurre con cualquier otro tipo de sociedad cooperativa, para constituir una de servicios públicos es necesario reunir un capital social, integrado por las aportaciones realizadas por los socios. La LCSA no fija un montante mínimo para el capital social pero, es obvio que éste habrá de estar en consonancia con la propia actividad societaria. Legalmente no se concibe el capital social como un fondo de explotación, sino como la referencia a la necesidad de contar con bienes susceptibles de valoración económica que permitan acometer una actividad empresarial ${ }^{46}$. Los Estatutos de la sociedad obligatoriamente han de concretar su cuantía (capital social estatutario), y esta cifra tendrá que respetarse por el patrimonio social contable, so pena de entrar en causa legal de disolución (art. 79.1.f).

${ }_{46}$ MARTIN REYES y OLMEDO PERALTA (2013): "El Capital social: concepto y funciones" en PEINADO GRACÍA (dir): Tratado de Derecho de Cooperativas, Vol 1, Tirart lo Blanc, p. 551. 
Otra peculiaridad significativa del capital social en la legislación de cooperativas es el papel socializador que desempeña, al estar abierto a la concurrencia de diversos tipos de socios, a los que el capital se acomoda de diversas maneras. De ellas interesa en este estudio resaltar los límites porcentuales del capital social que puede corresponder a cada tipo societario.

\section{A. Estructura del capital social}

La preocupación del legislador por la estructura del capital social de las cooperativas se justifica, entre otros motivos, por reducir el poder que pueda ostentar cada socio y también por dotar a la sociedad de independencia frente a descapitalizaciones provocadas por la salida y reintegración a sus socios ${ }^{47}$. De la conjunción de las previsiones de la LSCA y del RSCA derivan tres límites que operan sobre el capital social de una sociedad cooperativa de servicios públicos y que se establecen en función del tipo de socio. Son los siguientes:

a) El 45\% del capital social figura como límite máximo para las aportaciones de cada socio, tanto en la modalidad de socio usuario, como en la modalidad de socio que sea entidad privada con experiencia demostrada en el sector (art. 54.3 LCSA). Es un límite individual, es decir, establecido para cada uno de los socios.

b) El 49\% del capital social rige como límite máximo (y excepcional) para las Entidades Públicas promotoras ${ }^{48}$ (art. 54.3 LCSA). Al igual que el anterior, este es un tope legal individual. La DA $22^{\text {a }}$ LCSP que exige, como novedad, una participación pública mínima del 51\% del capital en las sociedades de economía mixta para aplicar la síntesis procedimental de adjudicación del contrato público, lo que podría suponer una importante contrariedad para la implantación de cooperativas de servicio público. Habría que recurrir al art. 104 TRRL que faculta a que el acuerdo constitutivo de empresas de economía introduzca "las especialidades internas tanto estructurales como funcionales que, sin perjuicio de terceros, exceptúen la legislación societaria aplicable". El requisito de que la medida sea necesaria para promover y desarrollar la empresa mixta se cumple sobradamente porque de no poder acogerse a dicho procedimiento de licitación no podría crearse la cooperativa, como se expuso en el epígrafe anterior.

c) El 25\% del capital social se fija como límite máximo para los socios trabajadores. A diferencia de lo previsto en los dos casos anteriores, el límite aquí no rige de

$47 \quad$ Ibídem, p. 552

48 VARGAS VASSEMONT critica, con razón en mi opinión, lo injustificado de este límite en el modelo cooperativo de la LSCA puesto que, teniendo en cuenta que ni los derechos políticos ni económicos de los socios están relacionados con el capital social que hayan suscrito, legalmente se desincentiva tener una mayor participación (2017: p. 380). 
forma individual para cada eventual socio trabajador, sino de forma colectiva para el conjunto de aportaciones que puedan realizar tal tipo de socios. Así se deriva de la dicción reglamentaria cuando especifica que también "podrán participar (...) las personas socias trabajadoras que presten su trabajo personal en la sociedad, en este último caso hasta alcanzar el veinticinco por ciento del capital de la misma".

Por consiguiente, una vez concretado estatutariamente el capital social de la cooperativa de servicios públicos podrá averiguarse el valor legal máximo de las participaciones de cada tipo de socio que la integre, de cara a la mejor estructuración interna de la sociedad cooperativa de servicios públicos y a facilitar la localización de los socios para la constitución de la sociedad.

\section{B. Aportaciones societarias de la Entidad local promotora}

El capital social de la cooperativa de servicios públicos no presenta ninguna modulación jurídica en cuanto a sus elementos, estando integrado por aportaciones de los socios. Generalmente las aportaciones serán dinerarias, aunque también podrán no serlo, siempre que se reúnan ciertos requisitos que trataremos enseguida. La aportación societaria es un negocio jurídico traslativo, por el que la sociedad cooperativa adquiere la titularidad de lo aportado. Dependiendo del momento en que se realiza la aportación, la LSCA distingue entre aportaciones constitutivas y sucesivas. Unas y otras pueden ser, a su vez, obligatorias o voluntarias.

Los Estatutos han de determinar el montante de las aportaciones obligatorias constitutivas, que ha de coincidir con el capital social estatutario. La LCSA exige que el capital social se suscriba íntegramente (art. 54.2) y que en el momento de la suscripción se desembolsen al menos un cincuenta por ciento de las aportaciones obligatorias constitutivas. Los Estatutos pueden establecer condiciones y plazos para el desembolso del resto de las aportaciones, en los tres años siguientes (art. 55.3).

El régimen jurídico de las aportaciones de los socios en las cooperativas de servicios público no tiene en el RSCA ninguna peculiaridad. Rige, en principio, las normas generales establecidas por la LSCA (art. 54 y ss) y por el RSCA en su desarrollo $^{49}$. Sin embargo, por lo que hace a la aportación de la Entidad pública, existen algunas especialidades jurídico-administrativas que han de traerse a colación.

Una de las más significativas, puesto que se separa de lo previsto en la LCSA, se refiere al desembolso de la aportación de la Entidad local. Como se conoce, la LCSA exige que el capital social se suscriba íntegramente, y que, al menos esté desembolsado en un cincuenta por ciento (art. 54.2). Sin embargo, tratándose de las

49 Para un comentario sobre las aportaciones de los socios al capital social bajo la vigencia de la LCSA y su reglamento, véase el apartado III del trabajo de VARGAS VASSEROT (2017: p. 379 y ss.) 
Entidades públicas, hay que tener en cuenta que, en el ámbito local, tanto desde el RSCL $^{50}$ como desde el RBELA ${ }^{51}$, se añade la obligación de desembolsar íntegramente el capital suscrito mediante aportaciones dinerarias desde el momento de su constitución. El mayor rigor para con las Entidades locales en lo referente a la inmediatez del desembolso dinerario es de suponer que facilita el desembolso que corresponda hacer al resto de los socios, aunque esto queda a lo que se decida en los Estatutos.

En cuanto al procedimiento administrativo para que las Entidades andaluzas realicen la aportación, hay que entender que, si bien la aportación a la sociedad implica para la Entidad pública una enajenación, realmente ésta no obedece a una venta de bienes patrimoniales en sentido puro, sino a la obligación de constituir una sociedad para la gestión indirecta de un servicio público ${ }^{52}$, junto con los socios previamente seleccionados. No es necesaria, pues, una licitación específica para la aportación de la Entidad local ${ }^{53}$. Con todo, la imperatividad de una participación mayoritaria pública en las sociedades de economía mixta de la nueva DA 22ª , conlleva que siempre pueda recurrirse a la adjudicación directa de bienes patrimoniales prevista en el art. 21.g LBELA ${ }^{54}$.

Además, el RSGL agrega una determinación relativa a los documentos para la constitución societaria, estableciendo que "el valor de la aportación de la Entidad pública local ha de fijarse, por todos los conceptos en la escritura fundacional de la cooperativa". La expresión "escritura fundacional" no creo que deba entenderse en el sentido literal, sino comprensiva del acta de la asamblea constituyente, que puede ser suficiente (sin necesidad de elevarla a escritura pública) para inscribir la cooperativa, de acuerdo con lo que dicta el art. 7 RSCA al desarrollar la LSCA.

50 En su art. 109.2 se lee que "El capital efectivo que aporten las Corporaciones locales deberá estar completamente desembolsado desde la constitución".

$51 \quad$ El art. 44.1 de esta norma prescribe que "Las aportaciones dinerarias de las Entidades locales a las sociedades (...) cooperativas (...) en las que legalmente tuvieren participación y cuyo objeto sea la prestación de servicios o actividades económicas desarrolladas en el ámbito de su competencia, deberán estar totalmente desembolsadas y representadas por sus correspondientes títulos".

52 Esta es la ratio decidendi en la STS (sala $3^{\text {a }}$ sección 4 ${ }^{\mathrm{a}}$ ) de 22 marzo 2006 (FJ 10), que hacemos nuestra. El problema jurídico planteado en este caso era resolver la laguna jurídica relativa al procedimiento administrativo para proceder a la venta de acciones de una sociedad mercantil pública de cara a la generación de una sociedad de economía mixta.

53 Otros autores prefieren explicar la innecesariedad de previa licitación específica para la designación del destinatario de la aportación afirmando que se trata de un supuesto de adjudicación directa. Así, CORRAL GARCÍA y LÓPEZ PELLICER: Reglamento de Bienes de las Entidades locales. El Consultor, 2001, p. 281, con apoyo en COBO OLVERA: Adquisición, utilización y enajenación de los bienes de las Entidades locales, El Consultor, 1997, p. 226 y ss.

54 Las cooperativas andaluzas de servicios públicos no podían beneficiarse de esta previsión en la medida en que la legislación andaluza de cooperativas restringe la participación pública al 49\%, límite que la DA $22^{a}$ LCSP obliga a saltar, de facto, como se ha explicado en el texto principal . 
Éste es el lugar también para recordar que las aportaciones de las Entidades locales, representadas por sus correspondientes títulos ${ }^{55}$, habrán de tener su reflejo en el Inventario General Consolidado de los Bienes y Derechos de la Entidad local, por ser ésta un deber establecido por la legislación patrimonial andaluza ${ }^{56}$.

Especial atención reclama el tema del tipo de bienes que pueden conformar las aportaciones de la Entidad pública. La LCSA establece como regla general que las aportaciones sean dinerarias ("se realizarán en moneda de curso legal" dice su art. 54.4), pero también se admiten aportaciones en especie, a condición de que se autoricen por la Asamblea General, y se hagan con "bienes o derechos evaluables". Sobre este aspecto, el RSCA no refleja ninguna especialidad al regular las sociedades cooperativas de servicios públicos, por lo que les resulta plenamente aplicable el art. 54.4 LSCA, que rige para todo tipo de cooperativas. Este artículo dispone que "Las aportaciones se realizarán en moneda de curso legal y, de autorizarse por la Asamblea General, podrán consistir en bienes y derechos evaluables económicamente, en cuyo caso, se estará a lo dispuesto en la normativa legal aplicable en lo que a su entrega y saneamiento se refiere. La expresada autorización podrá tener un carácter general, sin que sea preciso su acuerdo en cada caso. El régimen de valoración de las aportaciones no dinerarias se determinará reglamentariamente".

Estos condicionantes sirven para las aportaciones en especie que pudieran corresponder a los socios usuarios, trabajadores o empresarios seleccionados para conformar la Cooperativa de Servicios Públicos, y también, cómo no, para las de la Entidad pública. Pero respecto de éstas últimas, es menester averiguar si el régimen patrimonial administrativo propio de las Entidades Locales, en cuanto que sujetos jurídico-públicos, contiene alguna peculiaridad que suponga una condición adicional, o incluso una restricción, a las posibilidades de realizar aportaciones no dinerarias a una cooperativa de servicios públicos.

Llegados a este punto, hemos de suscribir en todo la opinión, común entre la doctrina, que advierte acerca de la improcedencia de realizar aportaciones no dinerarias al capital social a base de bienes demaniales, debido a las condicionantes constitucionales fijados para ellos en el art. $128 \mathrm{CE}^{57}$. En efecto, los principios cons-

55 Las modalidades de titulación recogidas en el art. 42.3 RSCA, al amparo del art. 55 LSCA, son tres: títulos o libretas de participación nominativos, fichas o relación nominal de socios con su correspondiente importe, y, finalmente, anotaciones en cuenta.

56 En efecto, el art. 59.2 LBELA prevé que "todo acto administrativo de adquisición, enajenación, gravamen o que tenga cualquier tipo de repercusión sobre la situación física y jurídica de los bienes se anotará en el inventario."

${ }^{57}$ Voces autorizadas en este punto son las de SANTIAGO IGLESIAS (2010): Las sociedades de economía mixta, ob. cit, p. 122 y ss; MONTOYA MARTIN (2011): "Gestión de servicios locales a través de empresas municipales y mixtas" en Tratado de Derecho Municipal, Iustel, vol. 3, p. 2943 y ss; PENDÓN 
titucionales de imprescriptibilidad, inembargabilidad, y muy especialmente el de inalienabilidad, resultan del todo incompatibles con una traslación de dominio a favor de la sociedad cooperativa como la que implica una aportación cuyo objeto fuera un bien demanial ${ }^{58}$. Nuestro ordenamiento se posiciona sin ambages a favor de que la titularidad de un bien demanial se mantenga en manos públicas (art. 5.1 LPAP ${ }^{59}$ ). Pero tan claro como esto es que existen títulos jurídicos habilitantes de cierto tráfico jurídico sobre los bienes públicos que transfieren a terceros derechos temporales de uso sobre bienes de dominio público, que no afectan a la titularidad del bien en sí misma considerada (pues mantienen a la Administración como propietaria) sino únicamente a su uso (graduable en cuanto a su exclusividad), y además son títulos susceptibles de valoración económica.

En ese sentido no tendría que descartarse la posibilidad de que el objeto de la aportación fuera una concesión demanial que, según prescribe el art. 97 LPAP $^{60}$ otorga a su titular (en nuestro caso la sociedad cooperativa) un derecho real sobre las obras, construcciones e instalaciones fijas que construya para el ejercicio de la actividad autorizada por el título de la concesión (la prestación del servicio público) y con "los derechos y obligaciones del propietario"61 durante la vigencia temporal

MELÉNDEZ (2013): "El capital social. Aportaciones al capital social" en PEINADO GRACIA (dir.): Tratado de Derecho de cooperativas. Tomo I. Tirant lo Blanch, 2013, p. 569. También la Dirección General de los Registros y del Notariado mantiene esta postura, como muestra su Resolución de 15 de julio de 2016 publicada en el BOE núm. 196, de 15 de agosto de 2016, que resuelve un recurso contra la denegación de inscripción en el Registro de la Propiedad, con ocasión de un concurso voluntario de acreedores por el que se procedía a la venta de una finca que se reputaba de dominio público y que se había aportado al capital de una sociedad mercantil. Asumiendo la doctrina de la muy conocida Resolución de 12 de septiembre de 1985, que negó la posibilidad de que por un ayuntamiento se pudieran aportar al capital social de una sociedad privada municipal diversos bienes de dominio público, y dejando muy claro que "no es posible legalmente realizar aportaciones sociales con bienes de dominio público, pues a ello se opone tanto el que el régimen del dominio público repele que pueda pasar su titularidad a una sociedad mercantil, como que el régimen de la sociedad mercantil repele que el capital pueda ser cubierto, en todo o en parte, con bienes de dominio público", se añade en 2016 que "además, la inalienabilidad de los mismos hace imposible su transmisión a una persona jurídica distinta del propio ente local titular del bien público, y, por otra parte, menoscaba la función de garantía patrimonial de los acreedores sociales que cumple el capital social. De ahí que la mayoría de la doctrina estime que la única aportación relativa a bienes de dominio público que resulta factible es la de derechos reales sobre los mismos, de igual forma que se hace con un concesionario, sin que sea transmisible su titularidad".

58 En este sentido, SANTIAGO IGLESIAS (2010: p. 125), con apoyo en MENÉNDEZ (1985): "Sociedad privada municipal y aportaciones de bienes de dominio público" en REDA n 47, p. 422.

59 Innecesario es recordar que su definición de bienes de dominio público es de aplicación general, de acuerdo con la Disposición Final $2^{\text {a }}$ de la LPAP.

60 De acuerdo con la Disposición Final $2^{a}$ de la LPAP, este precepto es de aplicación general (aptdo. 1) y también de carácter básico (aptdo. 2).

${ }_{61}$ Coincido con FERNÁNDEZ SCAGLIUSI en que hubiera sido más apropiado que la Ley equiparara al concesionario con un superficiario que con un propietario (2015: La rentabilización del dominio 
de la misma. Concebida como un derecho real, la concesión, se diseña legalmente en el art. 98 LPAP, como un derecho que, previa autorización administrativa, es susceptible de cesión o transmisión y también de hipoteca ${ }^{62}$ (si bien únicamente como garantía de los préstamos para financiar la realización de obras, construcciones e instalaciones fijas ubicadas en el dominio público objeto de la concesión). Como bien precisa FERNÁNDEZ SCAGLIUSI, la LPAP busca con ello "garantizar la plenitud del dominio dividido a favor del concesionario, otorgándole un derecho real sobre las construcciones que, desligado así del «suelo demanial» sobre el que se asienta, le permita realizar operaciones de transmisión, financiación e hipoteca sobre su derecho que no entren en colisión con los principios de inalienabilidad e imprescriptibilidad del dominio público" ${ }^{63}$. Con todo, no ha de ocultarse que la autorización previa y demás condicionantes que limitan la libre transmisibilidad del título concesional, pueden representar una dificultad para no pocas operaciones, y la imposibilidad de funcionar como garantía frente a los acreedores ${ }^{64}$.

Todo lo anterior nos lleva a postular que, si bien jurídicamente es posible concebir que la aportación de la Entidad pública pueda realizarse (total o parcialmente) con concesiones demaniales, la fórmula no ha de tomarse como la recomendada con carácter general, sino que es necesario valorar su oportunidad y conveniencia ad casum para poder analizar, a la vista del tipo de bien demanial y los diversos usos que pudiera acoger, las posibilidades prácticas de cumplir con las funciones designadas al capital de una sociedad cooperativa. En definitiva, habrá de considerarse de forma particular y a la vista de sus concretas características, la facilidad de la concesión demanial para ser trasformada en dinero en un embargo y ejecución ante la eventual necesidad de responder de las deudas sociales. No sólo, pues, importa el dato de la evaluabilidad del derecho concesional, como parece establecer la legislación cooperativa antes mencionada. Desde esta advertencia es como hay que entender, en mi opinión, el art. 23.2 LBELA: "Cuando se trate de sociedades mercantiles en cuyo capital social participasen íntegra o parcialmente, las Entidades locales podrán aportar la concesión demanial debidamente valorada".

público en tiempos de crisis: ¿nuevas tendencias coyunturales o definitivas? Tecnos, p. 210)

62 La Ley Hipotecaria también se refiere expresamente a las concesiones administrativas demaniales en su art. 107, cuando dice: "También serán hipotecables: (...) Sexto. Las concesiones administrativas de minas, ferrocarriles, canales, puentes y otras obras destinadas al servicio público, y los edificios o terrenos que, no estando directa y exclusivamente destinados al referido servicio, pertenezcan al dominio particular, si bien se hallen agregados a aquellas obras, quedando pendiente la hipoteca, en el primer caso, de la resolución del derecho del concesionario".

63 (2015: p. 205)

64 MONTOYA MARTÍN señala que, al tener que permanecer afectos al servicio público, los acreedores no tendrán acceso a estos bienes (2011: p. 2944). 
De este art. 23.2 LBELA comentaremos dos aspectos. El primero es que sólo aluda a las sociedades mercantiles, haciendo omisión de las sociedades cooperativas en las que tengan participación las Entidades locales, a las que, sin embargo, sí se ha referido, en su apartado 1, para regular la aportación con bienes patrimoniales. Lejos de considerar que este silencio ha de interpretarse como una prohibición de aportar concesiones a las sociedades cooperativas de servicios públicos, y teniendo en cuenta que nada obsta a que una sociedad cooperativa pueda ser titular de una concesión administrativa, bien puede sostenerse que se trata más de una imperfección de la norma provocada por un lapsus del legislador, que de un límite negativo al régimen de las aportaciones cooperativas.

En segundo lugar, del art. 23.2 LBELA hay que destacar que la habilitación para proceder a la aportación se condiciona a un cúmulo de requisitos, a saber:

a) la condición de socio en la cooperativa de la Entidad pública aportante. Este requisito deriva de algo obvio como es que solo los socios pueden realizar aportaciones. Por ello, el supuesto de hecho de la norma incorpora la exigencia de que la Entidad local participe en la sociedad. La aportación no es una simple donación gratuita, sino que tiene como causa la adquisición de la condición formal de socio integrante de la cooperativa. Como el precepto se redacta aludiendo a las sociedades mercantiles, se prevé tanto la participación íntegra como parcial. Sin embargo, tratándose de sociedades cooperativas, ya se sabe que no cabe constituirlas con un socio único, sino que son necesarios, al menos tres socios.

b) la debida valoración de la concesión que se aporta. Sobre este particular, el art. 45.4 RBELA puntualiza que ha de tratarse de una valoración técnica en la que deben tenerse en cuenta tanto el valor material de los bienes e instalaciones objeto de la concesión como su valor de explotación derivado de su carácter necesario para la prestación del servicio (art. 45 RBELA).

c) el carácter oneroso de la concesión. Se justifica este requisito en que es preceptiva la fijación de un canon, para cuya cuantificación, el art. 45 RBELA cuida de precisar que si la sociedad no va a prestar el servicio en régimen de monopolio, la cuantía del canon garantizará que se cumplan las exigencias de la legislación de la Unión Europea en materia de libre competencia.

La legislación patrimonial de las Entidades locales de Andalucía se preocupa de diseñar el expediente administrativo que debe tramitarse para cristalizar la aportación de concesiones a una sociedad de economía mixta. Según el art. 23 LBELA éste debe constar de un informe jurídico y de un estudio económico financiero, así como de una tasación pericial (independiente, por tanto) a través de la que se concrete el valor de la concesión al que se ha hecho mención anteriormente. Finalmente, la Ley realiza una atribución competencial al Pleno del Ayuntamiento para la apro- 
bación de la aportación concesional a la sociedad, que debe acordarlo por mayoría absoluta del número legal de miembros de la corporación.

Por último, hemos de referirnos a la previsión en la LBELA de que las concesiones demaniales y la de bienes demaniales afectos al servicio público pueden aportarse también bajo la fórmula de la prestación accesoria ${ }^{65}$ (retribuida o no), aunque haciéndose eco de la legislación mercantil ${ }^{66}$, prohíbe taxativamente que las prestaciones accesorias integren el capital social de la empresa. Es bien conocido que la figura de las prestaciones accesorias ${ }^{67}$, propia de las aportaciones sociales en las sociedades de capital, no recibe regulación alguna ni en la LSCA ni en su reglamento cuando tratan del régimen económico de las sociedades cooperativas, y mucho menos de las de servicios públicos. Surge, por tanto, la duda de su admisibilidad en las sociedades de economía mixta con forma cooperativa que pudieran promoverse por Entidades locales andaluzas ${ }^{68}$.

Finalmente apuntemos que existe autorizada doctrina ${ }^{69}$ que no ve impedimento en que la aportación al capital social cooperativo consista no en una concesión

65 MONTOYA MARTÍN (2011: p 2944) valora como acertada esta solución de aportación de bienes.

66 Según el art. 86.2 del Real Decreto Legislativo 1/2010, de 2 de julio, por el que se aprueba el texto refundido de la Ley de Sociedades de Capital, "en ningún caso las prestaciones accesorias podrán integrar el capital social."

67 Las prestaciones accesorias son colaboraciones de los socios que contribuyen al fin común societario y son objeto de obligaciones individuales frente a la sociedad, como las aportaciones en sentido estricto, pero se diferencian de ellas porque son, como su nombre refleja, obligaciones accesorias, complementarias de la principal de realizar las aportaciones sociales en forma de acciones o participaciones, y además nunca se incorporan al capital social. Son obligaciones de naturaleza social y origen estatutario. Las prestaciones accesorias se consideran vehículo apropiado para que los socios presten a la sociedad ciertas colaboraciones que tienen vedado su acceso a la aportación de capital pero que pueden resultan interesantes para la sociedad Véase al respecto JIMÉNEZ SÁNCHEZ, g. y DÍAZ MORENO, A. (2014): Derecho mercantil. Volumen $3^{\circ}$ Las sociedades mercantiles. Marcial Pons, p. 300-301.

68 Para que pudieran tener algún sentido no habrían de coincidir estas eventuales aportaciones accesorias con el derecho a "utilizar los bienes de dominio público necesarios para el servicio" que el art. 128 RSGL reconoce al concesionario de servicios públicos, cuya posición jurídica corresponde a la sociedad de economía mixta (art. 182 del Real Decreto 1098/2001, de 12 de octubre, por el que se aprueba el Reglamento General de la Ley de Contratos de las Administraciones Públicas: "En los contratos de gestión de servicios públicos la sociedad de economía mixta figurará como contratante con la Administración, correspondiéndole los derechos y obligaciones propios del concesionario de servicios públicos.").

69 Así, SANTIAGO IGLESIAS (2010: p. 134) no encuentra razón desde el punto de vista del Derecho Administrativo para valorar como aportación al capital social el derecho de gestión del servicio a una sociedad de economía mixta, por considerarlo valorable económicamente y susceptible de transmisión; o MOLTÓ CARBOLNELL (2002: p. 171), quien, dando por sentado tal posibilidad, se preocupa por la naturaleza jurídico-patrimonial que le pueda corresponder, decantándose por la de bien patrimonial; o GARRIDO GALLA, quien destaca que con tal aportación se superpondrían un contrato de concesión y otro de sociedad. (2002) Tratado de Derecho Administrativo, vol. II, p. 434. 
demanial sino en la concesión misma de gestión de servicio público ${ }^{70}$, como título que otorga a la Sociedad un derecho exclusivo ${ }^{71}$ de explotación y gestión sobre tal servicio, a su riesgo y ventura y, en cuanto tal, susceptible de valoración económica y transmisión.

\section{ORGANIZACIÓN, TOMA DE DEGISIONES. Y GONTROL AD- MINISTRATIVO SOBRE LAS CONDICIONES DE PRESTA- GIÓN DEL SERVICIO}

Unas de las características de las cooperativas es que ni la constitución y composición de los órganos de la sociedad, ni la adopción o impugnación de sus acuerdos se configuran teniendo en cuenta la composición del capital. A diferencia de lo que ocurre en las sociedades de capital, el porcentaje de participación en el capital cooperativo no representa la medida de los derechos de los socios, sino que, bajo la regla de "un socio, un voto", en las cooperativas de primer grado (como son las de servicios públicos) es el voto de la mayoría societaria el que puede constituir órganos sociales y adoptar acuerdos ${ }^{72}$. En este punto las cooperativas de servicios públicos se siguen las normas generales de la LSCA, y dos únicas pautas aportadas por el RSCA.

Al regular la organización de las cooperativas, la LSCA precisa que la dirección y administración corresponde a dos órganos preceptivos: la Asamblea General y el órgano de administración (art. 26) 73 . La Asamblea General es un órgano de funcionamiento no permanente, integrado por el conjunto de los socios de la cooperativa ${ }^{74}$. Es, por ello, el órgano supremo de expresión de la voluntad social en los asuntos que sean de su competencia legal o estatutaria (art. 27 y 28), tales como la aprobación de

70 Algunas Comunidades Autónomas sí han previsto esta modalidad. Así, por ejemplo, la Ley 7/1999, de 9 de abril, de Régimen Local de la Comunidad Autónoma de Aragón y la Ley 1/2003, de 3 de marzo de la Administración local de La Rioja. Sus arts. 215 y 216, respectivamente, al regular la gestión indirecta mediante sociedad mercantil con responsabilidad limitada o cooperativa, permiten que la aportación de las entidades locales pueda consistir "en la concesión del servicio u otra clase de bienes o derechos que tengan la consideración de patrimoniales y sean valorables económicamente."

71 El carácter exclusivo del derecho de explotación lo subraya MOLTÓ CARBONELL (2002): "Tres tipos de participación local en la empresa" en Revista de Estudios de la Administración Local núm 289, p 171. Destaca este autor que "no tendría sentido (...) conceder el ejercicio de una actividad de libre prestación".

72 VARGAS VASSEMONT (2017): "El capital social y otras formas de financiación en la cooperativa" en AA.VV.: Retos y oportunidades... ob. cit. p. 378, y "Régimen económico" en PEINADO GRACIA (Dir.): Tratado ... ob. cit. p. 552. En estos trabajos se describen otras funciones del capital social distintas de la organizativa.

73 Otros órganos de carácter potestativo se regulan en los arts. 40 a 45 LCSA. Para su comentario, consúltese el trabajo de MACÍAS RUANO (2017): "Órganos potestativos en el régimen jurídico andaluz de sociedades cooperativas (arts. 43-45 LSCA) en AAVV: Retos y oportunidades ... ob. cit. 297 y ss.

74 Véase PEINADO GARCÍA y VÁZQUEZ RUANO (2013): "Sociedades Cooperativas" en JIMÉNEZ SÁNCHEZ y DIÁZ MORENO: Derecho Mercantil. Vol · $3^{\circ}$, Marcial Pons, p. 981. 
cuentas anuales, la modificación estatutaria, el nombramiento y cese de los miembros del órgano de administración, etc ${ }^{75}$. El derecho al voto en la Asamblea (art. 31 LSCA) aporta una nota distintiva propia de las cooperativas. Mientras que en las sociedades de capital la potencia de voto del socio va unida a su participación en el capital, en las cooperativas, al amparo del principio democrático que inspira su estructura, gestión y control (art. 4), rige la máxima "un socio, un voto". Así, el art. 31 LSCA dice: "cada persona socia común tendrá derecho a un voto"76.

Evidentemente, estas reglas sitúan por definición a la Entidad local, en una posición de minoría frente al resto de socios en la Asamblea. Seguramente por ello, el RSCA permite aplicarles las especialidades de las cooperativas mixtas, para que, de acuerdo con el art. 106 LCSA, sus Estatutos fijen "los criterios de relación equitativa y proporcional entre los socios y socias que desarrollen cada una de las actividades, determinando, en su caso, los derechos y obligaciones de cada clase". Cabría plantear si esto permite una modulación del derecho a voto, en consonancia con las excepciones a la legislación societaria que ampara el art. 104.2 TRRL, e introducir el voto plural ponderado en las cooperativas de servicios públicos ${ }^{77}$. Este tipo de voto se contempla en la LSCA solo para las sociedades cooperativas de servicios, pero sin embargo la Ley estatal 27/1999 de cooperativas lo admite expresamente para los socios que sean entidades públicas (art. 26).

También se obliga a que en los órganos sociales exista una representación de cada actividad cooperativizada integrada en la sociedad, y se admite que los Estatutos reserven la Presidencia y Vicepresidencia a socios que desarrollen una determinada actividad. En las cooperativas de servicios públicos, habría que valorar cuál de los tipos de socios, en atención a su actividad y a lo que ésta signifique para el servicio público, podría tener reservados tales puestos.

Junto con la Asamblea General de Socios, toda cooperativa ha de contar con un órgano de administración, de carácter permanente. A este órgano la Ley le confiere el gobierno, la gestión y la representación de la sociedad cooperativa, ejercidos con sometimiento a la ley, a los Estatutos y a las directrices generales fijadas por la Asamblea General. La Ley le encomienda la gestión diaria de la cooperativa (art.

75 Para un comentario de las competencias de la asamblea general en la LSCA, véase CRUZ RIVERO (2017): "La asamblea general (I). Concepto, competencias, clases y convocatoria" en AAVV: Retos y oportunidades...ob. cit., p. 145 y ss.

76 Como excepción, para las cooperativas de servicio se regula el voto ponderado (art. 106 LSCA).

77 No han de esconderse las críticas a este tipo de voto por su escasa utilidad práctica y por lo dificultoso que resulta para adjudicar y contar, como advierte BAENA BAENA (2017): "La asamblea general (II). Constitución. Celebración. Impugnación de acuerdos" en AAVV: Retos u oportunidades...ob. cit., p.194. 
37.2), de forma que su buen funcionamiento asegura la adecuada prestación del servicio público, en nuestro caso.

La LSCA diseña tres tipos posibles de órgano de administración, a elección de los Estatutos. La fórmula general es el Consejo Rector (art. 36 a 41 LSCA), que al ser un órgano colegiado, a veces su régimen de funcionamiento resulta poco ágil para cumplir su cometido ${ }^{78}$. Sólo se admite la previsión estatutaria de una Administración única o una Administración solidaria (de dos personas) para cooperativas de menos de diez socios (art. 42 LSCA). Por lo improbable de una cooperativa de servicios públicos tan reducida, lo normal será que su gestión se lleve a cabo por un Consejo Rector $^{79}$.

Los Estatutos establecen la composición del Consejo Rector, con un mínimo de tres miembros que asumirían la Presidencia, Vicepresidencia y la Secretaría, pero sin máximo legal alguno, salvo que fuera de aplicación la DA $12^{\mathrm{a}} \mathrm{LBRL}^{80}$.

La Asamblea general elije por mayoría simple y en votación secreta a los administradores o los miembros del Consejo Rector, de entre los socios ${ }^{81}$ de la cooperativa $^{82,83}$ que estén libres de causas de incapacidad, prohibición o incompatibilidad

78 La observación crítica es de TATO PLAZA (2013): "Órganos sociales" en PEINADO GARCÍA (Dir): Tratado, ob. cit., p. 440.

79 Téngase en cuenta que el proyecto de ley de modificación de la LSCA contempla para el art. 36 que "No obstante, en las sociedades cooperativas de primer grado integradas por dos personas socias comunes los estatutos sociales deberán atribuir la administración de aquéllas a dichas personas administradoras, pudiendo elegir entre la Administración Única o Solidaria de la entidad."

${ }^{80}$ Los entes pertenecientes al sector público local, desde la modificación de la LBRL por la LR$\mathrm{SAL}$, tienen establecido un número máximo de miembros de su consejo de administración, que dependiendo de la clasificación que el Pleno de la Entidad local le asigne al ente en cuestión, variará de entre 15 a 9 miembros máximos (DA 12 a LBRL). Sin embargo, las cooperativas de servicios públicos no satisfacen las condiciones para engrosar el sector público local en la medida en que, directa o indirectamente, el capital social de la cooperativa no esté participado mayoritariamente por Administraciones Públicas, ni disponga de votos mayoritarios, ni tenga derecho a nombrar o a destituir a la mayoría de los miembros de los órganos de gobierno de la sociedad, ni el administrador único o la mayoría de los miembros del consejo de administración de la sociedad. Estos criterios son los recogidos en el art. 2 del Real Decreto 1463/2007, de 2 de noviembre, por el que se aprueba el reglamento de desarrollo de la Ley 18/2001, de 12 de diciembre, de Estabilidad Presupuestaria, en su aplicación a las entidades locales.

81 Como excepción, el art. 38.2 LSCA consiente que los Estatutos admitan consejeros que no sean socios pero cuenten con cualificación profesional, experiencia técnica o empresarial, y les otorga derecho a voto. No pueden superar en número al tercio de los consejeros que sí sean socios.

${ }_{82}$ Difiere en este punto el régimen de las sociedades de capital, donde la regla general es precisamente la contraria, es decir, que salvo que los Estatutos digan otra cosa, no es condición ser socio para poder ser nombrado administrador de la empresa (art. 212 Ley de Sociedades de Capital)

83 La LAULA nada determina sobre las condiciones para que una Entidad local pueda designar a la persona física de sus consejeros, pero sí lo hace el RSCL en su art. 108 al regular la gestión por empresa mixta con sociedades anónimas o de responsabilidad limitada. Allí se dispone que "Los representantes que 
(art. 48). Sin embargo, la designación de consejeros se limita si legal o estatutariamente se reservan puestos para representación de alguna clase de socio. Así, por reenvío del art. 101 RSCA al art. 106 LSCA, en las cooperativas de servicios públicos "deberá existir una representación de cada una de las actividades cooperativizadas integradas en la sociedad y, estatutariamente, se podrán reservar la Presidencia y Vicepresidencia a los socios y socias que desarrollen una determinada actividad".

Los acuerdos del Consejo Rector se toman por mayoría simple de los votos válidamente emitidos en cada sesión. No rige para el Consejo Rector el mismo principio democrático inspirador del derecho de voto que en la Asamblea General (un socio, un voto). Pese a ello, la eventual reserva de la Presidencia a la Entidad local, no le asegura necesariamente una influencia dominante sobre la cooperativa, pues, desde el punto de vista de los votos, la Presidencia únicamente sirve para dirimir posibles empates (art. 39.3 LSCA).

Puede plantearse, por otro lado, si resulta oportuno trasladar al régimen de la adopción de acuerdos de las cooperativas de servicios públicos, la previsión del art. 106 RSCL relativa a que los órganos de gobierno y administración de las sociedades mixtas (anónimas y de responsabilidad limitada) tomen ciertos acuerdos por una mayoría cualificada ${ }^{84}$, excepcionándolos de la regla general de mayoría simple, que es también la que rige en la LSCA. En la medida en que la mayoría cualificada exige ponerse de acuerdo en dichos asuntos, pero no prohíbe que esas decisiones puedan tomarse, cabe sugerir su incorporación a los Estatutos, apelando a las excepciones que el art. 104 TRRL permite hacer a la legislación de sociedades.

En otro orden de cosas, para hacer frente al posible déficit de cualificación profesional y técnica del Consejo Rector, la legislación andaluza de cooperativas prevé que los Estatutos pueden hacer uso de la figura de la Dirección (art. 47 LSCA), a quien se puede otorgar. facultades y poderes circunscritos a los asuntos concernientes al giro o tráfico empresarial ordinario de la sociedad cooperativa. Ni la LSCA ni

correspondan a la Corporación en los órganos de gobierno y administración de la Empresa serán nombrados por aquélla en la proporción de un 50 por 100 entre los miembros que la constituyan y técnicos, unos y otros de su libre designación y remoción". La incorporación al Consejo Rector de consejeros que sean concejales municipales (personal político), para lo que no se requiere preparación técnico-empresarial alguna, no parece lo más sensato, como bien ha destacado la doctrina, porque es la buena gestión de la cooperativa lo que está en juego (SANTIAGO IGLESIAS: 2017). Este sería uno más de los aspectos de los que debería ocuparse el legislador autonómico andaluz siguiendo el ejemplo del Decreto 179/1995, de 13 junio, por el que se aprueba el Reglamento de Obras, Actividades y servicios de las Entidades locales de Cataluña (art. 288), o el más reciente Decreto 347/2002, de 19 de noviembre, por el que se aprueba el Reglamento de Actividades, Servicios y Obras de las Entidades locales de Aragón (art. 307.5).

84 En concreto, RSCL establece esta exigencia para cuatro supuestos: "a) modificación del acto de constitución o de los Estatutos de la Empresa; b) aprobación y modificación de los planos y proyectos generales de los servicios; c) operaciones de crédito; y d) aprobación de los balances". 
el RSGA exigen una Dirección para las cooperativas de servicios públicos, pero sin embargo, el art. 106.3 RSCL establece que “(e)l cargo de Gerente recaerá siempre en persona especializada designada por el órgano superior de gobierno de la Empresa”. Aunque el precepto está orientado a sociedades de capital, a mi juicio, es perfectamente trasladable a sociedades cooperativas, por lo que tratándose cooperativas de servicios públicos sería obligatorio, o al menos, muy recomendable su previsión estatutaria.

Cuando se trata de la gestión indirecta de servicios públicos, el tema del control sobre las condiciones de prestación de los mismos no puede pasar inadvertido. La forma en que se erogue el servicio afecta al interés general tan directamente que reclama la posibilidad de supervisión administrativa. En este sentido, el art. 26 LAULA identifica a la Entidad local titular de la competencia sobre el servicio local de interés como garante de la buena marcha del servicio frente a sus destintatarios (acceso universal, igualitario, calidad y precio asequible a toda la población, en atención a los valores de cohesión social y territorial).

El RSCA dedica un apartado en su art. 99, del siguiente tenor: "las entidades públicas promotoras conservarán el control en cuanto a las condiciones de prestación de los servicios públicos". Sin embargo, en este mismo epígrafe, ha quedado constatado que el régimen de toma de decisiones de las cooperativas de servicio público no otorga a la entidad local socia ningún mecanismo para hacer prevalecer su postura frente al resto de los socios y garantizar, desde dentro, que las condiciones en que el servicio se presta por la cooperativa de servicios públicos sean satisfactorias.

¿Qué sentido, entonces, darle al art. 99 RSCA cuando afirma que "las entidades públicas promotoras conservarán el control en cuanto a las condiciones de prestación de los servicios públicos"? No especifica a qué tipo de control se refiere, ni tampoco cómo se ejerce o a través de qué mecanismo societario ¿Acaso apela al art. 104 TRRL para justificar todo tipo de excepciones estructurales y funcionales del régimen cooperativo?

En mi opinión el RSCA no hace otra cosa que introducir en el régimen cooperativo una aclaración a modo de limitación de la facultad decisoria y ejecutoria de la sociedad cooperativa de servicios públicos. No establece nada nuevo que no se contemplara ya en la LCSP: que sobre las condiciones de prestación del servicio la sociedad cooperativa de economía mixta no tiene la última palabra. No la puede tener porque, aunque la Entidad local se integre como socio en la cooperativa, ésta no es más que un contratista de la Entidad local, sujeto, por tanto, a las normas reguladoras del contrato de concesión de servicio. Y en este sentido nuestro Derecho ha venido reservando a la Administración contratante, "en todo caso (...) los poderes de policía necesarios para asegurar la buena marcha de los servicios de que se trate" 
(art. 287.2 LCSP), y simultáneamente obliga al contratista con una serie de cuatro obligaciones generales para todo servicio gestionado indirectamente (art. 288 LCSP), de las que tres están orientadas precisamente a la buena marcha del servicio. Se trata de los deberes relativos a la continuidad pactada con la que ha de prestarse el servicio, a las condiciones establecidas para permitir su utilización por los usuarios, al mantenimiento del buen orden del servicio y a la indemnización de daños a terceros derivados del desarrollo del servicio.

Consecuentemente, en nada influye la modalidad societaria elegida para la sociedad de economía mixta que gestione el servicio, pues los poderes de control de las condiciones de su prestación corresponden a la Entidad contratante con carácter general, por imperativo de la Ley y deben desarrollarse de conformidad con lo indicado en el contrato suscrito, que se eleva a parámetro de continuidad de la prestación del servicio, de su accesibilidad y de su buena marcha. Por eso es especialmente adecuado el verbo "conservarán" que tanto el RSCA como el LCSP utilizan para garantizar que los poderes de policía sobre estas actividades permanecen en la esfera jurídica del Ente contratante. Se trata de destacar la idea de que siempre le corresponden a la Administración titular del servicio, como responsable último del funcionamiento del servicio, sin que pueda desentenderse del mismo por haber puesto en marcha una gestión indirecta del mismo mediante una sociedad cooperativa de economía mixta.

\section{CONCLUSIONES}

Desde un punto de vista jurídico, hemos visto que las sociedades cooperativas de servicios públicos no son figuras del pasado, sino que siguen teniendo cabida en nuestro ordenamiento jurídico como una modalidad de sociedad de economía mixta. Cosa distinta es averiguar por qué estas cooperativas, contando con respaldo legal, no son figuras de nuestro presente, como muestra a las claras el Registro de Cooperativas Andaluzas, y, viendo el panorama de su regulación, vaticinar si en el futuro tendrán mejor acogida.

Las páginas precedentes ponen de manifiesto el desencuentro de las distintas normas que convergen, como piezas de un enrevesado puzle, en la regulación de las sociedades de economía mixta en general (desde la perspectiva de régimen local, patrimonial y contractual) y de las cooperativas de servicios públicos en particular. En éste último ámbito, la falta de atención del legislador es especialmente acusada, con una habilitación a reglamento a modo de cheque en blanco para que regule prácticamente todos sus pormenores. La valoración de esa regulación reglamentaria no puede ser muy positiva. Se diría que el RSCA de 2014 hereda de la LSCA el menguado interés por las cooperativas de servicios públicos. 
Desde la perspectiva ius publicista en la configuración de la sociedad de economía mixta, la cooperativa de servicios públicos ve mermado su ámbito de actuación por las modificaciones que incorpora la nueva LCSP. Esta Ley restringe la viabilidad procedimental de su constitución a los contratos de concesión de servicios y deja sin cobertura eventuales contratos de servicios por los que se gestionaran la prestación de servicios públicos. Mayor repercusión tiene la necesidad de que para acogerse a la síntesis procedimental de constitución (adjudicación directa), la LCSP de 2017 exija que la participación pública en la sociedad de economía mixta sea mayoritaria, cuando la LSCA, haciendo ya una excepción a la regla general, limita dicha participación pública en las cooperativas de servicio público al 49\%. La solución de modular este límite gracias al art. 104 TRRL pasa por ser más un parche que una verdadera solución, en la medida en que supone un elemento de desnaturalización de la figura cooperativa. Con todo, hay que destacar, por lo positivo, la nueva regulación por la legislación contractual de las condiciones de transmisibilidad de las participaciones societarias, lo que despeja dudas acerca de la vigencia del principio de libre adhesión y baja voluntaria en las cooperativas de servicios públicos.

Desde la perspectiva ius privatista, la flexibilidad que la legislación de cooperativas refleja en el amplio margen dispositivo de los Estatutos de la Sociedad, puede que sea un elemento que se vuelve en contra de la implantación de las sociedades cooperativas de servicio público. Son demasiados los factores que quedan huérfanos de toda orientación legal, con lo que puestos ante la disyuntiva de tener que hacer un diseño jurídico para la prestación de un servicio público bajo esta modalidad o bajo la más conocida de la sociedad de capital, es normal que la balanza se incline hacia esta última. Cuestiones como la distribución de funciones entre los distintos tipos de socios de la cooperativa de servicios públicos, la modulación del voto en la Asamblea General, la reserva en ella de la Presidencia y Vicepresidencia, la concreción del modelo de órgano de administración, o la viabilidad de excepcionar ciertos acuerdos de la regla general de la mayoría simple para su adopción por los órganos de gobierno y administración, son buena muestra de ello.

El proyecto de ley de modificación parcial de la LSCA, actualmente en tramitación parlamentaria ha desaprovechado la ocasión para abordar todas estas cuestiones, y ninguna de sus propuestas tiene como objetivo directo la mejora regulatoria de las cooperativas de servicios públicos. Con todo, la posibilidad de que estas cooperativas pudieran, tras la reforma, constituirse únicamente con dos socios podría eliminar muchos de los escollos jurídicos aquí mencionados, pero también arramblaría con la participación de usuarios y trabajadores en la cooperativa, una de sus características más atractivas. 